\title{
LAS PARADOJAS DE LA TRIBUTACIÓN. CIUDADANÍA Y POLIITICA ESTATAL INDÍGENA EN BOLIVIA, 1825-1900*
}

POR

\author{
MARTA IRUROZQUI \\ CSIC, Madrid
}

Este texto rastrea el acceso indígena a la ciudadanía a partir del estudio tanto de las normativas legales relativas a la propiedad indígena de la tierra y a su papel de contribuyentes del Estado, como de las discusiones políticas y económicas a que dio lugar el debate sobre la reforma agraria. Se mantienen tres premisas: primera, aunque el analfabetismo era el principal escollo de los indígenas para su incorporación a la ciudadanía, ese aspecto estuvo matizado por su condición de tributarios y por su situación jurídica respecto a la tierra; segundo, los esfuerzos estatales por eliminar las comunidades indígenas respondieron a una voluntad homogeneizadora, por considerarse la diversidad cultural un inconveniente para el desarrollo de la República y por desear una nación de ciudadanos; y tercero, se produjo un disenso progresivo en la creencia de la sociedad englobante en la asimilación de los indígenas como ciudadanos bolivianos.

Desde la constitución boliviana de 1825 la ciudadanía sólo podían ejercerla los varones mayores de edad, alfabetos, con propiedad o renta no adquirida en calidad de domésticos, posponiéndose la exigencia de alfabetismo hasta 1836 en espera a que el Estado desarrollara las medidas educativas necesarias. Aunque en el reglamento electoral de noviembre de 1839 reapareció la obligación de saber leer y escribir para participar en los comicios, permaneciendo dicha normativa hasta la revolución de 1952, se mantuvo la idea de que el gobierno tenía la responsabilidad de dignificar a la población, dotándola de los conocimientos o medios necesarios. Dado que la democracia se entendía como poder electoral, siendo el sufragio popular el origen legítimo de toda autoridad, la instrucción resultaba básica. Como únicamente «se hacía pueblo con ciudadanos libres», sólo un cuerpo electoral formado por individuos letrados sería capaz de emitir un voto

* Este trabajo se inscribe el Proyecto de Investigación PB96-0868 (DGES).

R. I., 1999, n. ${ }^{\circ} 217$ 
independiente, cuyo estricto cumplimiento por parte de las autoridades sería la condición de toda política moralizadora, patriota y de progreso nacional ${ }^{1}$. Ante esa concepción se plantean varias preguntas: primera, ¿la fijación en 1839 del requisito de saber y escribir en las leyes electorales significó que se consideraba que el Estado ya había hecho los esfuerzos suficientes para obtener una población alfabeta o se trataba de un principio laxo en la medida que el Estado no había podido cumplir sus objetivos?; segunda, ante una población mayoritariamente analfabeta, ¿cuál fue el peso relativo de los requisitos de propiedad y renta?; tercera, ¿Cómo afectó la normativa sobre la obligatoriedad de instrucción a colectivos como el indígena y en qué modificó su percepción particular y global como ciudadanos?; y cuarta, ¿la tributación se esgrimió como un argumento para el voto o, por el contrario, el pago del tributo fue la prueba de la no calidad moral del individuo para ejercer de ciudadano?

Si bien estas cuestiones serán objeto de discusión a lo largo del artículo para determinar las características del acceso indígena a la ciudadanía, es necesario adelantar algunos aspectos. En primer lugar, aunque la documentación oficial apunta a que el único impedimento de los indígenas para ser considerados como ciudadanos fue el analfabetismo, la práctica resulta mucho más imprecisa. No saber leer y escribir en castellano no fue siempre un escollo para la ciudadanía, ni ser alfabeto aseguró su disfrute. A juzgar por las discusiones recogidas en los redactores de las Cámaras de los Senadores y Diputados, la participación de los indígenas en calidad de ciudadanos estuvo matizada por criterios relativos a cómo se comprobaba la situación económica y laboral de los posibles votantes, a qué valor se daba a la condición de tributarios poseída por la mayor parte de los indígenas, qué situación jurídica tenían respecto a la tierra y a qué categoría indígena pertenecían.

En segundo lugar, se produjo un disenso progresivo en la asimilación de los indígenas como ciudadanos bolivianos, que, si bien estuvo sometido a variaciones regionales, terminó siendo general. En un inicio, el sufragio censitario no estuvo orientado a limitar la ciudadanía a los sectores con presencia económica, sino a asentar la figura del ciudadano letrado, referida al individuo en posesión del arte de pensar. La renta no significó una garantía de poder económico, sino de independencia de juicio y acción. Certificaba la absoluta responsabilidad de aquél que ejerciera el voto, ya que la holgura económica le proporcionaba tiempo libre para pensar en el bien común y ejercitar sin coacciones un voto reflexionado, siéndole natural asumir un comportamiento de responsabilidad cívica en beneficio de la república. El saber y la propiedad, únicos elementos capaces de asegurar la independencia de juicio y acción del individuo, se consideraban vir-

1 «La Asamblea de los 30». Editorial de La Industria, 30 de enero de 1888; José V. ALDUNATE, Memoria presentada al H. Congreso Nacional en 1888 por el Ministro de gobierno Dr. José V. Aldunate, Sucre, Imp. Sucre, 1888, p. IV.

R. I., $1999, \mathrm{n}^{\circ} 217$ 
tudes que un indio debía poseer si mediaba la capacidad regeneradora de la educación. Sin embargo, factores como la decadencia del tributo como fuente de riqueza fiscal, la creciente animosidad y politización de la población indígena a raíz de la reforma agraria y el acceso de los mestizos a la tierra sin la intermediación india, unidos a la supremacía del principio pseudo-científico de superioridad racial, invirtieron el proceso. La confianza en que las instituciones darían lugar a una nación de ciudadanos cedió paso a la convicción de que aquéllos que no pudieran ser blanqueados por el color y europeizados en la mentalidad y las costumbres serían excluidos de la nación por bárbaros e incivilizables. Como consecuencia del trasiego de la nación cívica a la nación civilizada ${ }^{2}$, el ambiguo estatus de ciudadana adquirido por la población indígena por su condición de tributaria y poseedora de tierra fue desdibujándose, apareciendo en su lugar la imagen de un indio rebelde, arcaico e incapaz, por su pasado de tiranía y sumisión, de asimilar el discurso del progreso, la importancia de lo público y el valor de lo nacional. Ineptos para integrarse en la nación «moral» boliviana, y por tanto de convertirse en hombres letrados con «honra y fama», los indígenas quedaron poco a poco enmarcados en una categoría cercana a la de «vagos, analfabetos de mala reputación y desconocidos», sobre todo si habían sido despojados de sus tierras y se veían obligados a trabajar como colonos o emigrar a las ciudades. Aunque seguían formando parte de la República, su incompetencia para actuar como «individuos libremente asociados», les distanciaba del resto de bolivianos, no quedando otra solución para redimirlos que una educación orientada al trabajo que fuera poco a poco eliminando sus taras y civilizándoles.

En tercer lugar, aunque existe una tendencia historiográfica a interpretar los esfuerzos de reforma agraria del siglo XIX como «la ampliación de la propiedad feudal criolla a expensas de las comunidades indígenas» ${ }^{3}$, prueba de la maldad política y esencia antidemocrática de las elites, los esfuerzos estatales por eliminar las comunidades indígenas no respondieron a una política anti-india, sino a una voluntad homogeneizadora, por considerarse la diversidad cultural un inconveniente para el desarrollo de la República y por desear una nación de ciudadanos. En el fracaso parcial de ese esfuerzo de asimilación cultural en favor de los valores criollos, entendido como modernización, intervinieron las resistencias indígenas a ver transformadas sus condiciones socioeconómicas, las consolidaciones y usurpaciones de tierras desligadas de las revisitas, el unas veces déficit y otras desinterés del Estado para controlarlas y evitar que atentaran contra la misma legislación

2 Estos términos acuñados por Mónica Quijada no hacen referencia a etapas fijas en el tiempo, sino que recogen síntomas cambiantes en cuanto al proceso de inclusión-exclusión nacional (Mónica QUIJADA, «¿Qué nación?. Dinámicas y dicotomías de la nación en el imaginario Hispanoamericano del siglo XIX». Cuadernos de Historia Latinoamericana, no. 2, AHILA, 1994, pp. 15-51).

3 Jorge Alejandro OvANDo SANZ, El tributo indígena en las finanzas bolivianas del siglo XIX. La Paz, Imp. del Comité Ejecutivo de la Universidad Boliviana, 1986, p. 17. 
agraria en nombre de intereses privados y el uso que los poderes locales, partidos y particulares hicieron del descontento, debilidad y movilidad indígenas.

Con el fin de ahondar en la compleja y contradictoria situación del indio respecto a la ciudadanía, este texto rastrea su acceso a la misma a partir del estudio tanto de las normativas legales relativas a la propiedad indígena de la tierra y a su papel de contribuyentes del Estado, como de las discusiones políticas y económicas a que dio lugar el debate sobre la reforma agraria. Asimismo, aunque el voto no fue el único elemento que definió la ciudadanía, la centralidad de las elecciones como el espacio de prueba del ejercicio de la misma, por considerarse que el sufragio materializaba la plena madurez ciudadana de un sujeto, explica por qué a lo largo de este artículo existe preocupación por vincular el disfrute de los indígenas a la ciudadanía no sólo a la tributación y la propiedad sino también a su presencia en las urnas ${ }^{4}$. Por último, pese a la importancia de los aspectos participativos y combativos en la conquista indígena de la ciudadanía ${ }^{5}$, en este trabajo sólo se analiza lo relativo a qué elementos les permitieron visibilizarse como ciudadanos y cuál fue la versión oficial al respecto. Pero aunque se trata de una historia «desde arriba» interesada en definir un escenario legal, no importan las leyes en sí, sino el margen de actuación que permitían y los factores que intervinieron en su continua redefinición. La división del texto en dos etapas, 18251866 y 1866-1900, no responde a que exista una clara diferencia temporal en la percepción del indígena como ciudadano, sino a la trascendencia de las medidas agrarias del presidente Melgarejo como síntoma de un cambio en el medio rural.

Para terminar, es imprescindible subrayar que este trabajo es deudor del debate sobre las transformaciones en la sociedad rural andina durante el siglo XIX. Sin entrar a discutir si las leyes y disposiciones estatales provocaron una expansión latifundista a costa de las comunidades indígenas o si en su mayoría éstas sobrevivieron a la integración boliviana a la economía mundial, la polémica historiográfica muestra que no se puede globalizar el análisis histórico de la cuestión comunal. Esto se debe a que, primero, hubo una diferente incidencia regional de las leyes agrarias en el tipo de tenencia de la tierra; segundo, los intereses eco-

4 Véase Marta IRUROZQUI, A bala, piedra y palo. La construcción de la ciudadanía política en Bolivia, 1825-1952. Premio «Nuestra América». Sevilla, Diputación de Sevilla, 1999 (en prensa).

5 Véanse: Marta IRUROZQUI, «Ebrios, vagos y analfabetos. El sufragio censitario en Bolivia, 1826-1925». Revista de Indias, no. 208, 1996, pp. 697-742; «La ciudadanía clandestina. Ciudadanía y educación en Bolivia, 1826-1952». Estudios Interdisciplinarios de América Latina y el Caribe (EIAL), vol. 10, no. 1 (Monográfico sobre la educación en América Latina), Jerusalem, 1999, pp. 61-88; Marta IRUROZQUi y Víctor PERALTA, «Ni letrados ni bárbaros. Caudillos militares y elecciones en Bolivia, 1826-1880». Secuencia. Revista de Historia y Ciencias Sociales, no. 42. México, 1998, pp. 147-176. Asimismo para lo relativo a los indígenas de la Amazonía boliviana consúltese Pilar GARCIA JORDAN, «¿De bárbaros a ciudadanos? Tutela, control de mano de obra y secularización en las misiones de los Guarayos (Amazonía norboliviana), 1871-1948». GARCIA JORDAN, Pilar, Fronteras, colonización y mano de obra indígena en la Amazonía Andina (siglos XIXXX). Lima, Pontificia Universidad Católica del Perú-Universitat de Barcelona, 1998, pp. 27-124. 
nómicos regionales provocaron diversas posiciones intelectuales respecto a qué hacer con los indígenas; tercero, la realidad de las comunidades y de sus reacciones no fue uniforme; y, cuarto, la expansión de la hacienda a su costa no fue siempre realidad, tanto por el intervencionismo paternal estatal, como por las acciones rebeldes, judiciales y políticas de los indígenas. Teniendo en cuenta esa complejidad, en este artículo se ha utilizado y reinterpretado bibliografía secundaria, pero no para ahondar en el problema de la tierra, sino para indagar a través de él en la dimensión pública adquirida por los indígenas en el siglo XIX. Al respecto no se aportan conclusiones cerradas, sino sugerencias en forma de preguntas que muestran cómo el proceso de conformación de la ciudadanía estuvo sujeto a una ambigüedad legislativa matizada por tópicos culturales y prácticas sociales.

\section{1. $1825-1866$}

Aunque en las Cortes de Cádiz de 1812 se planteó la sustitución del tributo por una única y directa contribución personal que deberían abonar «todas las clases del Estado», su implantación no tuvo éxito, tanto porque resultaba más onerosa para los indios, como por la oposición a tributar que demostraron «las clases antes exentas». En respuesta, el 1 de mayo de 1815 Fernando VII emitió una Real Cédula por la que lo restablecía con el nombre de contribución, siendo ésta recolectada en el Alto Perú por más de nueve años ${ }^{6}$.

Posteriormente durante la fase independentista, Bolívar expidió un decreto en Trujillo el 8 de abril de 1824 y tres en Cuzco el 4 de julio de 1825 que afectaban el sistema de autoridades y de tenencia de la tierra de la población indígena. Si por el primer decreto de Cuzco se abolían los cacicazgos, sin que ello supusiera que dejaran de ser tratados por las autoridades de la República como «ciudadanos dignos de consideración» o que perdieran las tierras sobre las que acreditaban títulos de dominio, por el segundo y tercer decretos de Cuzco se prohibió utilizar el trabajo de los naturales sin pagar un salario y sin que le precediera un contrato libre, se declaró a los indios dueños de las tierras en posesión y se ordenó la realización de nuevos repartimientos entre los indígenas desposeídos. Asimismo, Bolívar dijo que el Estado era el propietario legítimo de todas aquellas tierras que los particulares tuvieran en posesión precaria, no de aquéllas que hubiesen sido adquiridas en la época colonial a título de remate, composición o adjudicación. Esto afectaba a la población indígena, ya que gran parte de las tierras de comunidad entraban en la primera categoría. Sin embargo, como «el uso precario» que

6 Nicolás SANCHEZ ALBORNOZ, «Tributo abolido, tributo repuesto. Invariantes socioeconómicas en la época republicana». Nicolás SANCHEZ ALBORNOZ, Indios y tributos en el Alto Perú. Lima, IEP, 1978, pp. 189-190.

R. I., $1999, \mathrm{n}^{\circ} 217$ 
se les había concedido por el gobierno español era «sumamente perjudicial a los progresos de la agricultura y prosperidad del Estado», se nombró por el artículo segundo del decreto de Trujillo a los indios dueños de ellas, con la limitación de no poder enajenar las tierras que se les repartieran hasta 1850 . Esas disposiciones implicaron que las tierras poseídas por los indios como usufructo pasaron a convertirse en propiedades con títulos de dominio; lo que implicaba que se les otorgaba en materia agraria igualdad jurídica frente a los demás bolivianos. A su vez, por la resolución del 9 de noviembre de 1825, aclaratoria del tercer artículo del decreto de Trujillo, se estableció que las tierras sobrantes de comunidad se venderían en beneficio del Estado?.

Dado que las disposiciones anteriores fueron paralelas a los repartimientos de tierras entre los indígenas que no gozaban de ellas cabe preguntarse: primero, ¿los nuevos beneficiados recibían las tierras en calidad de propietarios o de usufructuarios de las mismas?; segundo, ¿gracias a tal dotación se convertían en indios originarios o se les consideraba forasteros con tierras? ¿o abandonaban esas categorías en calidad de pequeños propietarios sin adscripción étnica?; tercero, ¿el reparto de tierras y la venta de las sobrantes implicaba que ya no se preveían futuros repartos entre los indios?; cuarto, pese a lo anterior, ¿el Estado mantenía su papel de proveedor de los terrenos sobrantes que no hubieran sido vendidos?; quinto, ¿significaba esto que el Estado no renunciaba a su función de repartidor de dones o más bien se afirmaba la voluntad de terminar con su función tutelar de las comunidades y con ellas mismas?; y, sexto, si los repartos iban dirigidos a convertir a los indígenas en pequeños propietarios ¿podría decirse que con ello se buscaba también acabar con las diversas categorías en que se dividían $\mathrm{y}$, por tanto, con el estatus de indio?

La respuesta a tales interrogantes se complica si se tiene en cuenta que el 22 de diciembre de 1825 Bolívar suprimió el tributo, por considerarlo un impuesto particular por clase, y lo sustituyó por una contribución general que debía abonar todo hombre entre 18 y 60 años ya que la raza no constituía eximente. Si bien la eliminación del tributo podía presuponer la abolición de las comunidades indígenas, seguía sin esclarecerse el modo en que la categoría de tributario o extributario afectaba al tipo de tenencia de la tierra, es decir, si se concebía que ésta pertenecía al Estado o era propiedad indígena. Parece que lo que quiso Bolívar fue integrar a los indios a la sociedad republicana, borrando las distinciones de casta heredadas de la colonia y creando una nueva clase de pequeños propietarios a partir de las antiguas estructuras corporativas. De acuerdo al dogma liberal, estos campesinos parcelarios se convertirían en la columna vertebral del sistema político nacional y contribuirían a la creación de un próspero mercado de tierras y de productos agrícolas. Luego la venta de tierras sobrantes y la transformación

7 Alejandro ANTEZANA S., Estructura agraria en el siglo XIX. Legislación agraria y transformación de la realidad rural de Bolivia. La Paz, CID, 1992, pp. 25-37.

R. I., $1999, \mathrm{n}^{\circ} 217$ 
de los comunarios en pequeños propietarios iban destinadas a terminar con la decadencia de las provincias que provocaba trabajadores en posesión precaria o arrendamiento ${ }^{8}$. Sin embargo, ese objetivo quedó en suspenso por requerir para cumplirse un empadronamiento que no tuvo lugar, pese a que el reglamento correspondiente fue aprobado por Sucre el 29 de enero de 1826. La dificultad de la consideración legal que tenían las tierras ocupadas por los indígenas aumentó cuando en julio de 1826, el ministro de Hacienda Madero pidió a la Asamblea Constituyente la restauración del tributo en las áreas rurales y el mantenimiento en las ciudades de la contribución directa. A ello le siguió la Ley del 20 de septiembre de 1826, por la que se suspendían los decretos de Bolívar, siendo en el 31 de julio de 1827 cuando se restableció la antigua exacción, aunque la presión en favor de su mantenimiento no fue la misma en todas las regiones, debido a que tampoco lo hizo su incidencia fiscal ${ }^{9}$. Pese a que como ya se ha dicho antes la existencia de las comunidades se entendía vinculada al tributo, el hecho de que éste se impusiera y que se reconociera a sus miembros como principales contribuyentes del Estado ni clarificó si se las consideraba como entidades legales, ni resolvió si eran propietarias de los terrenos que ocupaban; más si se tiene en cuenta que, por un lado, el 12 de junio de 1827 el gobierno autorizó la transferencia de propiedades del Estado a particulares con el fin de dinamizar la economía del país, pero, por otro, se reconoció en la Resolución de 13 de mayo de 1826 que las comunidades no se entendían como bienes nacionales, sino como posesiones indígenas ${ }^{10}$. Veamos más de este proceso fluctuante.

El 28 de febrero de 1831 se dictó el reglamento de la revisita de tierras que tenía como objeto la matriculación y empadronamiento de los indígenas para la regulación de las tasas de contribución, declarándose en la ley de 28 de septiembre de 1831 a los indígenas contribuyentes propietarios de los terrenos en cuya pacífica posesión se hubieran mantenido por más de diez años y debiendo ser obligación de los párrocos y autoridades que tal medida fuese leída y explicada a los indígenas. Esta decisión, basada en los principios de propiedad y personería jurídica individual, implicó el reconocimiento de los indígenas como propietarios individuales de la tierra que ocupaban, y por tanto, la negación de la comunidad como organismo colectivo propietario con capacidad de desarrollar procesos legales. De hecho, por la Orden Suprema de 7 de febrero de 1834 se dispuso que ningún tribunal de la República debía admitir peticiones a nombre de las comunidades originarias en forma colectiva, puesto que los «indígenas podían demandar y pedir lo que convengan» de modo particular, pudiendo ser demandados sus intereses comunes mediante un apoderado. Para facilitar lo anterior el decreto del

8 Erick D. LANGER, «El liberalismo y la abolición de la comunidad indígena en el siglo XIX». Historia y Cultura, no. 14, p. 61.

9 Sánchez Albornoz, (7), pp. 190-199; William Lee LOFSTROM, El mariscal Sucre en Bolivia. La Paz, Editorial e Imprenta Alenkar, 1983, pp. 331-359.

10 Antezana, (8), pp. 47-49. 
6 de abril de 1837 restableció el Ministerio de Protector de Indígenas, destinado a defender lo declarado por la ley de 28 de septiembre de 1831 mediante la representación judicial de los naturales, siendo posteriormente revocado el 7 de julio de 1838 y destinados sus fondos al financiamiento de escuelas elementales en las poblaciones provinciales ${ }^{11}$.

Por este decreto los indígenas fueron definidos como «las personas que pagan la única contribución personal, denominada por los españoles tributo, sus padres, mujeres e hijos» ${ }^{12}$. Es decir, se pagaba el tributo tanto por la posesión de tierras, como por la calidad de indígena. Dado que muchos mestizos se habían empadronado como indios para obtener tierra ${ }^{13}$, es posible inferir que ser tributario y poseer el estatus de indio no menoscababa los derechos ciudadanos. Al contrario, la posesión de tierra de comunidad además de convertir al individuo en sujeto conocido, luego en vecino del pueblo, imposibilitaba su reclutamiento militar, ya que por poseer la condición de contribuyentes estaban exentos de éste por la Orden Circular de 28 de junio de $1838^{14}$.

A favor de la importancia del enraizamiento socioterritorial del individuo para ser asumido como sujeto activo nacional estuvo también la interpretación sobre la renta. En la Convención Nacional de 1843 se discutió el alcance de este requisito como prueba de que un individuo gozaba de la suficiente independencia para poder dedicarse al ejercicio de pensar que era en última instancia lo que le permitía ser ciudadano. El problema surgió en torno a la categoría de pobre de solemnidad. El diputado Salinas rechazó que a los sujetos englobados bajo esos términos se les excluyera de la ciudadanía argumentando que las rentas fijadas no eran representativas de la autonomía económica que podían garantizar a una persona, ya que si por un lado la ley electoral negaba el voto a aquél que no alcanzara una renta anual de 200 pesos, era probado que esa renta bastaba a muchos habitantes de Cochabamba y Santa Cruz para vivir bien. Asunto diferente era que

11 Colección oficial de leyes, decretos, órdenes y resoluciones supremas que se han expedido para el régimen de la República Boliviana. Impresa de orden del gobierno supremo con anotaciones y dos índices. Tomo IV, Que comprende el tiempo corrido desde 22 de julio 1835 hasta fin de diciembre de 1837. Sucre, Imp. de López, 1857, pp. 251-253; Colección oficial de leyes, decretos, órdenes y resoluciones supremas que se han expedido para el régimen de la República Boliviana. Impresa de orden del gobierno supremo con anotaciones y dos índices. Tomo $\mathrm{V}, Q u e$ comprende el año de 1838. Sucre, Imp. de López, 1857, pp. 249-250. Citado en Raul CALDERON JEMIO, «Años de ambigüedad: propuestas y límites de la política y legislación de tierras durante la consolidación republicana (Umasuyu y Paria, 1825-1839)». Estudios bolivianos, no. 4, La Paz, Instituto de Estudios Bolivianos, 1997, p. 117

12 OVAndo, (4), p. 46.

13 El reglamento del 28 de febrero de 1831 dispuso que «con respecto a las demás castas, se arreglarán los padrones a la costumbre, amparándolas en la posesión en que se hallen de no satisfacer contribución; a menos que disfruten de repartimientos de tierras de comunidad en cuyo caso serán matriculados los originarios» (Idem, p. 37).

14 Idem, p. 46.

R. I., $1999, \mathrm{n}^{\circ} 217$ 
esa renta hubiese sido adquirida en condición de doméstico, porque esa situación anulaba la voluntad del individuo, lo tornaba dependiente y, por tanto, desautorizaba el voto libre. Por ello proponía que se excluyese del derecho al sufragio a los que no tenían «interés en la cosa pública como los proletarios» cuya voluntad no era independiente ${ }^{15}$. A juzgar por lo expresado en la Convención Nacional de 1880 , la categoría de pobre de solemnidad y no la de proletario fue la utilizada con la población indígena ${ }^{16}$, luego ésta no quedaba englobada en la categoría de doméstico y eso le abría el paso a la ciudadanía. Pero para concretarla seguía teniendo que cumplir el requisito de renta. Esto tampoco resultaba un impedimento si se tiene en cuenta que por la naturaleza de los sistemas fiscales de la época, no era tanto la riqueza o la producción lo que otorgaba la ciudadanía política, sino la propiedad inmobiliaria y, en particular, la propiedad de la tierra. Es decir, el criterio de selección de los sujetos políticos, justificado generalmente con el argumento de que sólo la independencia de juicio garantizaba el bienestar económico, implicaba un determinado tipo de enraizamiento socioterritorial, que, a su vez, explicaba por qué los representantes eran idealmente los dirigentes reconocidos y naturales de la comunidad ${ }^{17}$. Como la población indígena era una veces propietaria y otras poseía la tierra, eso sin olvidar que las revisitas no se habían concretado y que en la práctica seguían existiendo las comunidades, es probable que el tributo se esgrimiera como prueba de renta para disfrutar de la ciudadanía política. De ser cierto, y teniendo en cuenta que para los indígenas ciudadanía era sinónimo de contribución ${ }^{18}$, se plantean varios interrogantes ligados a la participación política de los indígenas: primero, ¿el resguardo del pago del tributo podía presentarse ante las Mesas Inscriptoras como una prueba de cumplir con el censo?; segundo, ¿de satisfacerse lo primero, la propiedad comunal daba un acceso colectivo o individualizado a las urnas?, es decir, ¿podían votar todos los miembros varones, mayores de edad de una comunidad o sólo podría hacerlo uno de ellos en calidad de representante?; tercero, ¿qué pasaba con los indígenas no originarios?, ¿los indígenas forasteros con tierras poseía su mismo estatus legal?, ¿entraban los indígenas forasteros sin tierras en la categoría de domésticos por trabajar como arrendatarios las propiedades de los primeros?; y cuarto, ¿qué ocurría con los mestizos que por tener tierras de comunidad tributaban como indios? ¿en calidad de qué emitían el voto?. Además, dado que todo indígena tributaba, ¿era suficiente su calidad de contribuyente para votar o la

15 Redactor de la Convención Nacional del año 1843. La Paz, Litografía e imprentas Unidas, 1926, pp. 222-257.

16 Redactor de la Convención Nacional del año 1880. La Paz, Litografía e Imprentas Unidas, 1926, tomo II, p. 506.

17 Raffaele RomANELLI, «Sistemas electorales y estructuras sociales. El siglo XIX europeo». Salvador FORNER, Democracia, elecciones y modernización en Europa, Madrid, Cátedra, 1997, pp. 31-32.

18 Archivo Nacional de Bolivia (en adelante ANB). Ministerio de Hacienda. T. 16, no. 22. 
contribución no significaba nada si no iba acompañada de tenencia de la tierra?; de ser así, ¿votaban todos los originarios y los forasteros con tierra o sólo los primeros?, ¿se trataba de un voto individual o únicamente lo ejercía un comunario elegido por la comunidad como su representante?.

La ductilidad para cambiar de estatus que ofrecía la tenencia de tierras de comunidad estuvo ligada a la necesidades fiscales del Estado, que, entre 1827 y 1866, se vio apremiado a ampliar su espectro de recaudación debido a la disminución del número de tributarios. Para frenar el proceso, no sólo admitió como tales a los mestizos, sino también distribuyó tierras vacantes a los indígenas sin tierra e incluso liberalizó su definición fiscal mediante el ingreso voluntario en calidad de tributarios de viejos, mujeres y niños, libres en principio de cargas tributarias. De hecho, el decreto de 26 de enero de 1838, por el que Santa Cruz prohibió la venta de tierras de los tributarios, no implicó la defensa de los comunarios contribuyentes en contra del avance de la hacienda, sino la necesidad gubernamental de ingresos para mantener al ejército y hacer frente a las presiones de Chile y Perú. El presidente acusó a los indígenas de vender ilegalmente sus terrenos, sin acatar el decreto de 4 de julio de 1825, que prescribía que habiéndolos recibido en propiedad no podían transferirlos hasta el año 1850, agregando que las ventas eran contraproducentes para el tesoro estatal y la población tributaria, pues el primero quedaba privado de la contribución indigenal y la segunda perdía sus tierras:

«Los impuestos personales forman la principal y más efectiva renta de la hacienda pública y el gobierno que tiene comprometida su palabra para establecer el crédito nacional, levantar obras de utilidad pública y defender por ahora la dignidad e independencia de la República, amenazadas por nuestros enemigos exteriores, correspondería mal a las esperanzas de la Nación y faltaría a sus empeños, si no cuidase de los progresos de las rentas nacionales y de su más fácil, pura y exacta recaudación. A este propósito nada es más conducente que la legalidad de los empadronamientos y la extirpación de las arbitrariedades, fraudes y connivencias, que en los últimos periodos han disminuido notable y sucesivamente y preparado la extinción de la contribución personal» ${ }^{19}$.

Si bien medidas como el decreto del 26 de enero de 1839, que declaraba nulas las enajenaciones y ventas hechas por los indígenas y ordenaba a través de un procedimiento sumario que se les restituyesen los terrenos vendidos ${ }^{20}$, inciden en la idea de que el mantenimiento del tributo y la protección estatal del indígena

19 Colección oficial de leyes, decretos, órdenes y resoluciones supremas que se han expedido para el régimen de la República Boliviana. Impresa de orden del gobierno supremo con anotaciones y dos índices. Tomo V, Que comprende el año de 1838. Sucre, Imp. de López, 1857, pp. 89-90. Citado en CALDERON, (12), pp. 57-58.

20 ANTEZANA, (8), pp. 54-55. 
tributario estuvo ligada a las necesidades del erario público, ello no es contrario a que posibilitasen la continuidad de la tenencia indígena de la tierra. En este sentido, Gustavo Rodríguez y Erick Langer subrayan que el Estado, a través de su política fiscal, mantuvo un comportamiento colonial que favoreció la supervivencia e integridad territorial de las comunidades, con lo que ponen en duda el discurso sobre la continua agresividad del Estado sobre éstas ${ }^{21}$. Pero esa consecuencia convivió con la creencia general de que la vida comunal era contraria a las necesidades de civilización del país. A eso se unió que, si en los primeros años de vida independiente se había abogado por declarar a los indios propietarios de sus terrenos, en la década de 1840 se asentó la sospecha de que los terrenos comunales pertenecían al Estado boliviano. Este podía asignar «sus» tierras a los comunarios, dotarles de reducidas superficies o consolidarlos en la totalidad de sus posesiones, pero era siempre «suya» la capacidad de redistribuir y reglamentar el funcionamiento de las tierras ocupadas por los indios en calidad «enfitéutica», tal como consta en la Circular del 14 de diciembre de 1842:

«Son propiedad del Estado, las tierras que poseen los originarios, no debiéndose considerar éstos, sino como una especie de enfiteutas que pagan cierta cantidad al señor del dominio directo por el usufructo» 22 .

Por esta misma circular se señaló que sería competencia de las autoridades resolver los problemas sobre terrenos de una misma comunidad, mientras que los pleitos entre comunidades serían resueltos por el fuero de la jurisdicción ordinaria. Esa afirmación llevaba implícita no sólo que el Estado era el propietario de las tierras de comunidad, sino también su capacidad para realizar reasignaciones territoriales, siendo esta función la que le permitía asumir un carácter benefactor. Pese a ello, la consideración de si todas las tierras de comunidad eran propiedad del Estado o sólo las en apariencia inutilizadas o sobrantes se mantuvo como interrogante. Prueba de ello son tanto la Instrucción de Ballivian del 13 de febrero de 1843 de realizar «una visita formal y escrupulosa de todos los terrenos sobrantes, baldíos y que por algún título corresponden al Estado», para que pudiera hacerse una equitativa distribución de los mismos entre los indígenas cuyos repartimientos no estaban en proporción con la cuota que satisfacían, como la Resolución aclaratoria del ministro de Hacienda, Pedro Buitrago, de 4 de julio de 1844 que señalaba que sólo se consideraban tierras fiscales los terrenos sobrantes

21 Gustavo RoDRIGUEZ OSTRIA, «Entre reformas y contrarreformas: las comunidades indígenas en el Valle Bajo Cochabambino, 1825-1900». Data. Revista del Instituto de Estudios Andinos y Amazónicos, no. 1, La Paz, 1991, p. 179; Erick LANGER, «Persistencia y cambio en las comunidades indígenas del sur de Bolivia en el siglo XIX». Data. Revista del Instituto de Estudios Andinos y Amazónicos, no. 1, La Paz, 1991, pp. 61-83.

22 ANTEZANa, (8), p. 56. 
y baldíos ${ }^{23}$. Sin embargo, las afirmaciones de Gustavo Rodríguez acerca de que a fines de 1844 Sempértegui buscó en cada cantón posibles «tierras del Estado», encontrando algunas ocupadas por «particulares» y otras poseídas «en demasía por indígenas», por lo que alarmado procedió a la distribución de las mismas, dando a los originarios nuevos lotes y convirtiendo a forasteros en originarios y los forasteros sin tierra en forasteros con tierra y que las asignaciones realizadas fueron aprobadas en 1846 por el gobierno central pese a las protestas de los indios por las asignaciones ${ }^{24}$, muestran no sólo a un Estado ejerciendo su autoridad mediante su actuación como propietario distribuidor de tierras, sino también la ambigüedad existente respecto a lo que se entendía como propiedad individualizada y comunal de los indígenas y los límites de la misma. No se olvide que aunque se declaró a los indios propietarios de las tierras poseídas nunca se llegaron a efectuar las revisitas y empadronamientos que les hubieran garantizado tal propiedad. Ese hecho, unido a las posteriores revocaciones y reposiciones de las leyes de Bolívar motivadas por las necesidades fiscales, hace pensar que aunque el sistema de autoridades indígenas había sido desarticulado y los gobiernos consideraban a las comunidades un resabio corporativo del antiguo régimen, en la práctica las comunidades seguían funcionando bajo la lógica del triple vínculo colonial entre el tributo, el reparto de tierras comunales por parte del Estado y la posesión indígena de la tierra.

Si la corona había mantenido la capacidad contributiva de los indígenas asegurándoles el disfrute de tierras, la supresión del tributo implicaba que el repartimiento de tierras no procedía, luego si éste se realizaba podía inferirse que el Estado republicano actuaba como propietario de las tierras dejándoselas a los indios en calidad de usufructo a cambio de la contribución. Además, esa concepción equívoca sobre el origen de la propiedad de la tierra era alimentada también por los indígenas en la medida que presionaban al Estado para que repartiese terrenos mediante el argumento de que si no disponían de tierras no podía satisfacer la contribución. Erick Langer relata que en 1852 los apoderados de los ayllu Coriguaya, Sullca-Capaanco, Hilacapaanco, Calaacala y Omasuyos, de la viceparroquia de Tiquina pidieron al ministro de Interior que se les devolviesen las tierras que habían sido usurpadas ilegalmente en 1807 por el cacique Mariano Titoatauchi. El argumento empleado por los comunarios fue que en la medida que el Estado les proporcionaba terrenos, les consideraba y protegía sus derechos, ellos servían y pagaban la contribución indígena, por lo que no entendían que se permitiese «a cualquier particular hacerse dueño y apropiarse de la comunidad en perjuicio del mismo Estado y de los que contribuyen» ${ }^{25}$. Los abusos

23 Idem, pp. 56-62.

24 Rodriguez, (22), pp. 179- 189.

25 Archivo Departamental de La Paz (en adelante ADLP). J.A. Exp. «Civil seguido por los comunarios de la Vice Parroquia de Tiquina contra el coronel José Gregorio Palacios y su mujer 
desligados de acciones como las denunciadas explican que las comunidades no se restringieran al ámbito local, sino que se involucraran en los procesos políticos nacionales, por lo que se hace necesario revaluar el tópico de comunidades aisladas y de un Estado que no tenía presencia en el espacio rural.

La identificación indígena de los gobiernos a los que debían oponerse o secundar queda ilustrada durante el gobierno de José de Ballivián. La permanente crisis del Tesoro nacional, provocada por los fuertes gastos militares y burocráticos, llevó al gobierno a realizar un cobro anticipado del tributo. Como esto constituía una agresión contra el calendario tributario indígena, no sorprende la impopularidad del presidente en el altiplano paceño, ni el apoyo indígena a sus enemigos, José Miguel de Velasco y Manuel Isidoro Belzu ${ }^{26}$. Durante el gobierno del segundo no hubo disposiciones legales que directamente regulasen la propiedad de los indígenas originarios y las relaciones de producción agrarias. Pero ello no supuso que no existieran medidas que incidiesen en su situación, como la Circular de octubre de 1848, mandada a los prefectos de los departamentos, en la que Belzu ofrecía «justicia para todas las clases y garantía para todos los ciudadanos», siendo ejemplo de ello la prohibición de los festejos del día de navidad con

\footnotetext{
Isabel Titoatauchi sobre la propiedad de los terrenos de isicachi y otros nombres». Paquete, no. 9, 1851-1852. Citado en LANGER, (9), p. 149.

26 Aunque las referencias sobre el apoyo dado por los indígenas a los políticos apenas explican lo esperado por los indios por su ayuda, ni cómo se elaboraron sus acuerdos con las autoridades provinciales, ni cuáles fueron los mecanismos que los regulaban, la mención de tales vínculos ofrece una imagen política de éstos que cuestiona la narrativa sobre su marginalidad en la conformación nacional. Asimismo, las alianzas entre comunidades indígenas y autoridades locales y el hecho de que éstas en ocasiones actuaron como portavoces de las primeras requiere una revaluación historiográfica de la naturaleza de sus relaciones que estuvo ligada con el vacío dejado por las autoridades naturales y las estrategias de los ayllus por defender sus tierras comunales. No se olvide que la prohibición a fines del siglo XVIII de cualquier forma de privilegios originarios (Roberto Choque CANQui, «Los caciques frente a la rebelión de Túpak Katari en La Paz». Historia y Cultura, no. 19, pp. 83-93). y la posterior abolición del cacicazgo mediante los decretos bolivarianos hizo que los antiguos curacas, en su afán por recuperar poder social y económico, pasaran a convertirse en hacendados y a utilizar la ley para legitimar su toma de territorios del ayllu, con el consabido debilitamiento del mismo, ya que perdía miembros para el trabajo colectivo y la tributación. Mientras los ex-caciques se convertían en hacendados con ayuda gubernamental, los corregidores les reemplazaron en el cobro de la contribución y empezaron a recibir algunos de los antiguos privilegios consistentes en terrenos reservados para ellos y turnos de comunarios para trabajarlos. Esa situación se complica si se tiene en cuenta lo señalado por Tristan Platt respecto a que no sólo la dependencia de los corregidores y sus subalternos del excedente generado por los comunarios les hizo buscar una buena relación, sino que fue esa convivencia la que favoreció su acceso a las tierras de comunidad (Tristan PLATT, «La experiencia andina de liberalismo boliviano entre 1825 y 1900 : Raíces de la Rebelión de Chayanta (Potosí) durante el siglo XIX». Steve STERN (comp.), Resistencia, rebelión y conciencia campesina en los Andes, siglos XVII al XX. Lima, IEP, 1990. pp. 261302). Este aspecto resulta de gran relevancia si se atiende a las redefiniciones de estatus que encerraron las revisitas iniciadas en las décadas de 1860 y a los cambios que eso implicó en la concepción de lo indio y de su consideración pública.
} 
los que los gobernadores de provincia, corregidores y prelados acostumbraban dar la bienvenida a las autoridades superiores de paso por su jurisdicción, por considerar que tales recepciones eran organizadas con los recursos de los vecinos, en especial, de los comunarios ${ }^{27}$.

Durante el gobierno de José Córdova, por la Resolución del 22 de diciembre de 1855, previo dictamen fiscal, se declaró que los indios contribuyentes tenían expeditos sus derechos civiles y políticos, luego eran aptos para emitir su voto en las elecciones, agregando que su ejercicio no les privaba de las excepciones acordadas por ley ${ }^{28}$. Esa declaración contuvo la voluntad de convertir a los habitantes de Bolivia en ciudadanos bolivianos, ya que se añadió que todo prefecto debía impulsar Sociedades Protectoras de la Instrucción Primaria para establecer escuelas de niños y niñas en los cantones. Para ello, en la Circular del 3 de septiembre de 1856 se notificó a los Prefectos que

«mientras la instrucción primaria no cese de ser una especie de privilegio social, los derechos políticos que la Carta concede a condición de saber leer y escribir, sólo aprovecharán a una limitada minoría: que la libertad de prensa no llenará todo su objeto y que no será realizable en toda su benéfica extensión el sistema representativo que hemos aceptado, desde que la enseñanza pública no se halle en armonía con las instituciones patrias» ${ }^{29}$.

En espera de que dicha población adquiriese los atributos de la ciudadanía, el decreto de 18 de enero de 1858 consideró «que la clase indígena por su condición desvalida y por su falta de instrucción merece la protección inmediata del gobierno», por lo que se ordenó que todos los fiscales interviniesen a favor de las causas de los indios para evitar el abuso de las autoridades. Asimismo, aunque no se anuló la prestación de servicios forzados de los indios al Estado, sí se negó a las autoridades bajo el argumento de que «en la redistribución de los servicios públicos» éstos habían sido injustamente recargados y el gobierno no deseaba prolongar la situación en que esa «desgraciada clase» se hallaba reducida, sino restablecer «en estos individuos la dignidad del ciudadano» ${ }^{30}$. Junto a la anterior medida, el 16 de enero de 1858, el ministro de Hacienda, Tomas Frías, estableció una

27 Circular de Manuel Isidoro Belzu a todos los prefectos. La Paz, 16 de octubre de 1848. Citado en Juan Ramón Muñoz Cabrera, Apuntes cronológicos de la campaña emprendida sobre el sud por el ejército libertador al mando de S. E. el General Isidoro Belzu. Sucre, Imp. Beeche y Ca., 1848 , p. 17. Citados en Raúl CALDERON JEMIO, «En defensa de la dignidad: el apoyo de los ayllu de Umasuyu al proyecto belcista durante su consolidación (1848-1849)». Estudios bolivianos, no. 2, La Paz, Instituto de Estudios Bolivianos (UMSA), 1996, pp. 108-123.

28 Colección Oficial. Nueva Serie, I, p. 125. Citado en Josep M. BARNADAS, Apuntes para una Historia Aymara. Cuadernos de Investigación CIPCA no. 6, La Paz, Cipca, 1978, p. 44.

29 Colección Oficial. II, pp. 53-54. Citado en Idem, pp. 44-45.

30 Colección Oficial. I, pp. 107-110. Citado en Ibidem.

R. I., $1999, \mathrm{n}^{\circ} 217$ 
circular que suspendía las adjudicaciones gratuitas de terrenos; lo que generó inestabilidad entre el sector indígena, entre otras razones debido a que la retirada de la moneda feble boliviana conllevó una crisis monetaria que marginó a amplios sectores rurales del acceso a la moneda por quedarse sin circulante. A fin de calmar los ánimos, se expidió la Orden Suprema de 27 de agosto de 1858, por la que no sólo se respetaban todas las posesiones de las comunidades, sino que se declaraban no suspendidas las adjudicaciones para los indígenas que las poseían a título de contribuyentes ${ }^{31}$.

En general, la actitud oficial de protección hacia el indio estuvo en consonancia con el espíritu de los primeros reglamentos electorales, por el que aunque la ciudadanía estaba sujeta a la alfabetización y a la propiedad o renta no adquirida en calidad de doméstico, se consideró al Estado responsable de que todos lo habitantes de Bolivia cumplieran la primera exigencia. Si bien su compromiso debía concluir en 1836, las continuas referencias a la necesidad de impulsar la educación indígena demuestran que se consideraba que el Estado debía continuar impulsando la educación de los nacionales. Dado lo precario de tal gestión ${ }^{32}$, es posible que en la práctica las autoridades se mostrasen tolerantes en la exigencia del requisito de saber leer y escribir, siempre y cuando se adujesen contribución y tenencia agraria. De todos modos, como tanto los indígenas originarios, como los forasteros con tierras podían aducir tales «cualidades», queda en duda si los dos grupos intervenían en las elecciones o sólo lo hacían los primeros. Este tema resulta de interés en la medida que su constatación informaría de si el Estado respetaba las divisiones corporativas a la hora de reconocer ciudadanos o, por el contrario, su designación era ajena al estatus que dictase la costumbre comunal. La resolución de ese interrogante no sólo informaría del grado de autoridad estatal, sino que también permitiría precisiones en lo relativo a la consideración pública que poseían los mestizos vecinos de los pueblos que ostentaban el grado de indios para disfrutar tierras de comunidad. Respecto a éstos, lo que sí puede afirmarse es que el hecho de que aceptasen ser matriculados como indígenas revelaba que el pago del tributo no rebajaba su calidad moral, o al menos no hasta que las revisitas les facilitaron convertirse en propietarios de las excomunidades sin ostentar el estatus de tributario o indio.

Aunque el tema de la propiedad indígena de la tierra fue discutido entre 1830 y $1850^{33}$, el debate sobre el modo en que incidían las formas de organización

31 OVANDO, (4), pp. 65-67.

32 José María Dalence opinaba que los tributarios «no conocen bien su arte, ni los instrumentos que deben emplear en cada una de las operaciones que exige la agricultura», requiriéndose una educación que podría impulsarse fomentando escuelas parroquiales, aunque tal remedio resultaría dificultoso de impulsar debido a la carencia crónica de fondos estatales (José María DALENCE, Bosquejo estadístico de bolivia. la Paz, Ed. Universitaria, 1975).

33 Julian Prudencio, el ex-juez de paz de Mizque dudaba en 1844 de la viabilidad del desarrollo agrícola mientras los indígenas fueran reacios a acumular riquezas por dejarse llevar por prácti- 
rurales en el desarrollo económico se desenvolvió en la década de 1860. La preocupación por el logro de la estabilidad financiera complejizó la necesidad estatal del tributo con el problema de cómo sanear la hacienda pública, siendo con ello nuevamente afectada la población indígena, ya que la solución implicaba la abolición de las comunidades. De hecho no hubo discusión a ese respecto, como tampoco en lo referente a los derechos del Estado sobre la propiedad de los terrenos comunales sobrantes, sino sólo en lo concerniente a las formas, mecanismos y estrategias más eficaces para lograr su desaparición. Veamos un resumen de la confrontación de ideas respecto al porvenir de las comunidades en función de la superficie que el Estado, propietario de las tierras comunales, debía entregar a los indígenas ${ }^{34}$.

Jorge Mallo ${ }^{35}$ defendió la propiedad indígena individual de la tierra, pero reconoció al Estado como propietario de los terrenos comunales sobrantes al proponer que las arrendara. Mediante esta medida y la sustitución de las cargas impositivas coloniales -tributo, diezmos y primicias- por un impuesto a la propiedad urbana y rural se aliviaría el déficit del Tesoro Nacional. Melchor Urquidi ${ }^{36}$ coincidió en que la tierra sobrante debía ser declarada propiedad del Estado y subastada, imponiéndose un catastro basado en el valor de la propiedad. Aunque el cochabambino Miguel María Aguirre ${ }^{37}$ reconoció la importancia de esas medidas e insistió en los defectos del tributo por gravitar de modo no proporcional sobre los indígenas, propuso que para evitar su posible insurrección por la venta de los terrenos comunales sobrantes se distribuyeran éstos entre los indios, quedándoles prohibido venderlos hasta que no supieran leer y escribir. José Vicente Dorado ${ }^{38}$ estuvo en desacuerdo con esa iniciativa por considerar que hacer depender la libertad de venta de una circunstancia incierta significaba imposibilitar un libre mercado de tierras, ya que «el indígena de la campaña» no daba muestras «de prestarse a la civilización ni aspira(ba) a salir del estado de atraso e ignorancia en que viv(ía)». La única forma de cambiar esa circunstancia era abolir las comuni-

cas de «embriaguez y superstición» (Julian PRUDENCIO, Principios de economía política aplicados al Estado actual y circunstancias de Bolivia. Sucre, Imp. de Beeche, 1845).

34 Estas discusiones están extraídas de LANGER, (9), pp. 64-69; RODRIGUEZ, (22), p. 186; AnTeZANA, Estructura agraria ..., p. 78; Ovando, (4); Víctor PERAlTA y Marta IRUROZQUI, «Los bolivianos y el indio. Patrimonialismo y modernización en Bolivia, siglo XIX». Henrique URBANO (comp.). Modernidad y tradición en los Andes. Cusco, CBC, 1992, pp. 163-190.

35 Jorge MALLO, Aplicación económica cambiando el sistema rentístico de la república conforme a las costumbres modernas. Sucre, Imp. de Beeche arrendada, 1861.

36 Melchor URQUIDI, Bases para la reforma de la hacienda y contabilidad pública de Bolivia. Cochabamba, Imp. Los Amigos, 1861; Indicaciones sobre finanzas y sistema rentístico. Sucre, Tip. Pedro España, 1862. 1863.

37 Miguel María AguiRre, Apuntes financiales para Bolivia. Cochabamba, Imp. del Siglo,

38 José Vicente Dorado, Proyectos de repartición de tierras y venta de ellas entre los indígenas. Sucre, Tip. Pedro España, 1864.

R. I., $1999, \mathrm{n}^{\circ} 217$ 
dades, lo contrario era «perpetuarlo en la eterna ignorancia y atraso en que qu(ería) mantenerse», siendo el único resultado de ello que continuara aislado, ajeno a «nuestras agitaciones y luchas políticas», como «un Estado aparte, indiferente de todo punto a los acontecimientos y transformaciones que vive la clase blanca y sirviendo de obtáculo a los progresos y reformas». Convencido del profundo proceso de descomposición socioeconómica experimentado por esta población, Dorado propuso el reparto con plenos derechos de propiedad de las tierras de comunidad entre sus miembros, siendo los terrenos sobrantes repartidos entre los forasteros sin tierra. Esa medida unida a la conversión del tributo de personal en territorial no sólo los convertiría en industriosos mestizos, sino que también permitiría la libre venta de sus propiedades a los hacendados, convirtiéndose en colonos que asegurarían a largo plazo la prosperidad rural. El potosino Pedro Vargas ${ }^{39}$ no sólo estaba de acuerdo con que era necesario «arrancar a esta clase de sus atrincheramientos, enrolarla en las demás y formar una sóla nación, restituyéndole sus derechos y abriéndole el vasto campo de la civilización», sino también con que el indígena liberado de sus antiguas trabas comunales se transformaría. De ahí que propusiera su abolición y el reparto de la tierra entre los que la trabajaban, imponiéndose un impuesto de propiedad. Pero conocedor de que no renunciarían a la tierra se opuso a que les diesen la plena propiedad de la misma para que pudieran venderla, considerando más adecuado darle «el derecho de propiedad enfitéutica sin restricción alguna».

En suma, la discusión mencionada se redujo a dos propuestas sobre el lugar que se asignaba a los indígenas en el desarrollo histórico de la civilización futura. Mientras una planteaba la disolución jurídica y cultural de las comunidades mediante la individualización de la propiedad territorial colectiva, otra abogaba por la asimilación de los comunarios a la civilización bajo la forma de colonos de haciendas, coincidiendo ambas en que la desaparición de las comunidades beneficiaría a los intereses de la nación. Esa concepción implicaba:

Primero, una voluntad de eliminar pervivencias organizativas corporativas. Esto suponía tanto disolver las comunidades como entidad colectiva, como desconocer que los terrenos sobrantes formaban parte de la dinámica de organización y permanencia de la misma. Al contrario de lo sostenido tradicionalmente a nivel historiográfico, las autoridades no ignoraban el sistema de distribución interna de la tierra en las comunidades, por el que los terrenos denominados sobrantes eran en realidad tierras de barbecho o tierras en reserva destinadas a nuevas familias en las redistribuciones periódicas o tierras alejadas de la comunidad según el sistema agrícola de pisos ecológicos. Su aparente desconocimiento obedecía a la voluntad de limitar la base territorial de las comunidades, el ejercicio de poder local que se derivaba de las distribuciones internas de terrenos, el con-

39 Pedro VARGAS, Indicaciones económicas para la reforma del sistema tributario de Bolivia. Potosí, Tip. Municipal, 1864, p. 18.

R. I., $1999, \mathrm{n}^{\circ} 217$ 
trol fiscal que conllevaban tales reparticiones y el monopolio de los padrones para el pago del tributo. El afianzamiento de una autoridad estatal fuerte implicaba la progresiva supresión de los poderes locales autónomos y el disciplinamiento de los mismos a favor del Estado, porque sólo así podía garantizarse la gobernabilidad y la estabilidad política consecuente. La insistencia de los decretos y circulares en reconocer al Estado como propietario de las tierras comunales y las prácticas gubernativas de repartir paternalmente las tierras entre los indígenas obedecían a un esfuerzo de construcción nacional en el que el fortalecimiento del Estado como instancia directiva máxima responsable de la regulación de la autoridad era fundamental para la marcha de las instituciones republicanas. Además, las comunidades no sólo desestabilizaban el esfuerzo de uniformización política del Estado por entenderse como micropoderes corporativos, sino también porque fortalecían las redes clientelares de los vecinos de los pueblos. El desempeño del cargo de corregidor, que implicaba en muchas ocasiones realizar funciones antes destinadas a los caciques, ahondó las vinculaciones entre indígenas y vecinos. Eso conllevó un mayor control de la tierra por parte de estos últimos que reforzó los liderazgos locales. El empleo que éstos hicieron de la animadversión de las comunidades a las revisitas para transar con el Estado nuevos espacios de poder ejemplifica las dificultades de la autoridad central para gobernar sobre el territorio nacional. En suma, si bien el Estado padeció de una debilidad, en parte evidenciada por su dependencia fiscal del tributo y la dificultad de imponer un impuesto territorial a todas las propiedades rurales y urbanas, el duelo Estado versus comunidades indígenas mostraba su persistente esfuerzo por visibilizarse a lo largo del siglo XIX y primeras décadas del siglo XX.

Segundo, la política estatal contra las comunidades no sólo procedía de eliminar los poderes que mediaban entre los individuos y el Estado y regular la actividad de las instituciones, sino también partía de la consideración de que tales entidades creaban diferencias entre los habitantes del país que impedían el progreso. La coexistencia de culturas sumamente heterogéneas constituía un lastre para la construcción de una monoidentidad colectiva que garantizara el éxito de Bolivia como nación. De ahí que en todo el debate se vinculase la ciudadanía indígena a la desaparición de elementos que diferenciararan a los indios del resto de la población. Al respecto Jorge Mallo argumentaba que el tributo debía ser abolido, porque constituía un resabio del odioso pasado colonial y discriminaba «a una categoría de ciudadanos sólo por su raza», al ser un impuesto personal y no un impuesto a la producción. Miguel María Aguirre también era de la misma opinión y consideraba al tributo «una contribución más imperfecta que la capitación», por ser general, y no reducida a los indios. La idea acerca de que éstos serían incapaces de adquirir ciudadanía plena y de participar en la vida económica y política del país, debido a las trabas impuestas por las instituciones coloniales vigentes, fue seguida también por Melchor Urquidi, defensor de instalar escuelas en el área rural para educar a los indios e integrarlos a la vida nacional, y

R. I., $1999, \mathrm{n}^{\circ} 217$ 
por Pedro H. Vargas, favorable a «enrolar a esta clase» en las demás y formar una sóla nación, restituyéndole sus derechos y abriéndole el vasto campo de la civilización». Por último, Vicente Dorado consideró que las barreras corporativas impedían una aplicación igualitaria de la ley, sobre todo porque consideraba que su acceso a la civilización no provendría de que los indígenas aprendiesen a leer y escribir. Como ello no les convertiría en propietarios agrícolas con sentido empresarial, la solución radicaba en «sacar la tierra de su poder». Aunque la propuesta de Dorado suponía quitar a gran parte de los comunarios su acceso a la tierra en calidad de propietarios, de su discurso interesa resaltar que tanto la propiedad de la tierra como el pago al Gobierno de las cargas públicas eran aspectos que elevaban al indígena «a la noble clase de ciudadano en ejercicio».

Dado que esa visión final de Dorado coincide con las afirmaciones de los otros autores citados, a partir del debate sobre la supresión de las comunidades pueden inferirse algunas consideraciones sobre el derecho de los indígenas a la ciudadanía. En primer lugar, el acceso de los indígenas a ésta implicaba contribución fiscal y propiedad de la tierra. En segundo lugar, la calidad de contribuyente y de propietario agrícola hacía referencia a dos formas paralelas de entender la ciudadanía, una relacionada con el principio de representación funcional y otra con el principio plebiscitario, que denotaban la convivencia de nociones de antiguo régimen y republicanas. Según la primera, los indígenas podían asumirse como ciudadanos al garantizar al Estado el cumplimiento de sus deberes tributarios gracias a formar parte de una institución colectiva, la comunidad indígena, cuyos sistemas de colaboración permitían el pago del tributo al Estado que era lo que aseguraba al indígena el disfrute de la tierra; es decir, dado que entre el Estado y los indígenas mediaba una corporación, su acceso a la ciudadanía era grupal, luego no existía una lealtad directa entre el Estado y los indios en cuanto a individuos. Según la segunda, los indígenas podían cumplir con sus deberes tributarios gracias a gozar individualmente de una propiedad cedida por el Estado, luego la comunidad dejaba de actuar como la base de provisión económica que tenía el indio para cumplir con los deberes con el Estado, por lo que carecían de sentido su existencia y el mantenimiento de solidaridades colectivas. Aunque la tendencia estatal fue imponer la segunda forma de ciudadanía, su incapacidad para realizar una revisita total y reprimir la sublevación indígena consecuente, permitieron que en la práctica se prorrogase la primera. En tercer lugar, pese a que hubo propuestas, como las de Dorado, que planteaban reducir al indígena a colono, lo que impediría a los indios beneficiarse de la ciudadanía por convertirse en domésticos, la tendencia oficial a querer transformarlo en pequeño propietario reafirmaba un afán integrador de la población mediante la supresión de diferenciaciones de tipo estamental. El medio para bolivianizarlo sería la educación, como se constataba en el hecho de que los panfletistas considerasen que los indígenas alcanzarían la plena madurez ciudadana, expresada en realizar transacciones comerciales sin la tutela estatal, cuando fueran alfabetos. Eso informaba de 
que el único impedimiento real para el pleno disfrute de la ciudadanía por parte de los indígenas popietarios era el leer y escribir en castellano, ya que cumplían lo relativo a la propiedad y a la contribución.

Tercero, la intención homogeneizadora de la población proveniente del discurso liberal provocó una voluntad de desindianizar la imagen nacional de Bolivia. Sin embargo, a la vez que se produjo ese fenómeno, la función remodeladora del medio agrario implícita en las revisitas favoreció una reindianización de éste en la medida que los indígenas se aferraron a su antiguo estatus y a su tradicional relación con el Estado, temerosos del proceso de «proletarización» que se desligaba de su conversión en pequeños propietarios. Si bien en un inicio contaron con la ayuda de los vecinos de los pueblos que no tenían títulos de propiedad de las tierras que ocupaban, el hecho de que las revisitas permitiesen «mil fraudes» que les facilitaron su consolidación como propietarios hizo que ya no les interesase conservar la categoría fiscal de indios originarios o forasteros. Esto no sólo supuso que ese estatus perdiese validez social, sino también la progresiva ruptura de la convivencia entre el vecino y el indio, sobre todo a partir de la reforma de 1874. En suma, si en un inicio los principios liberales incidieron en la necesidad de borrar diferenciaciones culturales, la resistencia india a la disolución de las comunidades, provocada más por los abusos y la falta de alternativas que por el deseo corporativo, unida a una concepción tradicional sobre la inferioridad de lo indígena, reinvirtió el proceso hasta el punto que se consideró cada vez más dudoso que la educación uniformizara a la población.

\section{2. $1866-1900$}

Esbozadas algunas connotaciones sobre el acceso de los indígenas a la ciudadanía que se extraen del debate sobre el futuro de las comunidades, queda por relatar cómo los distintos gobiernos concretaron las diversas propuestas. Abrumado por las dificultades financieras y los salarios atrasados, el presidente José María Achá siguió los consejos de su ministro de Hacienda Urquidi en el Decreto de 28 de febrero de 1863, por el que se dispuso la distribución de pequeñas parcelas, de tres topos en tierras regadas y seis en esteriles y de dos y cuatro topos, entre los indios originarios y los forasteros, respectivamente, y la venta de las tierras sobrantes; suponiendo lo primero la reducción de muchas de sus posesiones agrarias y lo segundo la pérdida de recursos. En la Asamblea Nacional Ordinaria reunida en Oruro en junio de 1863 los parlamentarios Julio Méndez, Anselmo Nieto y el Dr. Galdo rechazaron esa disposición por considerarla «una solemne violación a la propiedad otorgada a los indígenas por la Ley de 28 de septiembre de 1831». Su posterior obrogación hizo que Pablo Barrientos, oficial mayor encargado del ministerio de Hacienda, propusiera que el modo de asegurarse que los terrenos produjesen más renta estaba en declarar a los indígenas

R. I., $1999, \mathrm{n}^{\circ} 217$ 
propietarios de los terrenos que poseen, con la restricción de no poderlos enajenar sin haber aprendido a leer y escribir, y en «distribuir equitativamente los sobrantes y baldíos, incluso los poseídos abusivamente por los blancos, entre los forasteros sin tierras». En consonancia con las propuestas anteriores, la resolución suprema de 12 de septiembre de 1864 dictada por Aguirre en calidad de nuevo ministro de Hacienda de Achá declaró vigentes las Circulares de 16 de enero y 27 de agosto de 1858 al decir que «los terrenos ocupados por los naturales con sus ganados y sembrados no sean mensurados ni avaluados, pues no se pueden adjudicar a nadie» ${ }^{40}$.

En contraste, durante el gobierno del general Mariano Melgarejo se optó por favorecer que las tierras ocupadas por los indígenas pudieran comprarse por «la clase civilizada», con la ventaja de que las comunidades desposeidas pasaran a convertirse en colonos del comprador. El Decreto del 20 de marzo de 1866 estableció que el indígena que dentro de 60 días, después de notificado, no recabara su título de propiedad abonando la suma de 25 a 100 pesos quedaba privado de la propiedad sobre su fundo rústico; siendo la Orden Suprema de 31 de julio de 1867, firmada por el ministro de Hacienda Manuel de la Lastra, la que prescribió las reglas que debían observarse para la venta de los terrenos de comunidad. La legitimación de ambas disposiciones se produjo cuando la Asamblea Constituyente de 1868 sancionó la Ley del 28 de septiembre que decía que las tierras poseídas por la raza indígena y conocidas con el nombre de comunidades se declaraban propiedad del Estado, con lo que se aprobaban las ventas realizadas según el Decreto del 20 de marzo de $1866^{41}$. En cuanto al tributo, aunque la ley de 1866 obligaba a los indios a seguir pagándolo, el 8 de octubre de 1868 fue suprimido. Con la intención de imponer un sistema impositivo que gravara a todos los ciudadanos de la república, se declaró que debía cumplirse con dos impuestos, uno predial y otro personal, estando sujeto a este último todo varón adulto de 21 a 25 años $^{42}$.

Sobre las ventas realizadas en esa etapa, voces críticas de la época dijeron que muchas fueron ventas clandestinas no registradas en los libros del Tesoro, tasaciones realizadas sin mensura o con mensuras falsas, adjudicaciones arbitrarias y extensión de títulos de propiedad sin el previo pago de lo tasado, debido a que se compraron terrenos de comunidad como liquidaciones de sueldos devengados $^{43}$. A nivel oficial también parece confirmarse esa versión porque, aunque no hay cifras exactas de lo vendido y ganado por el Estado, se afirmó que la venta de las comunidades no había solventado el déficit del Estado al ser mal-

40 ANTEZANA, (8), pp. 71-73.

41 Idem, pp. 84-87; RODRIGUEZ, (22), pp. 186-187.

42 SANCHEZ Albornoz (7), p. 208.

43 El decreto de 1 de junio de 1868 dispuso que la deuda pública procedente de los sueldos devengados de los empleados de la administración de 1865, 1866 y 1867 se amortizaría aplicando el valor de los devengados a la compra de tierras de comunidad (ANTEZANA (8), p. 89).

R. I., $1999, \mathrm{n}^{\circ} 217$ 
vendidas. Respecto a la estructuración de la propiedad, pese a que existe una tendencia historiográfica a decir que durante esta etapa se consolidaron las haciendas, los estudios de Gustavo Rodríguez, Robert H. Jackson y Alberto Rivera Pizarro indican para el caso cochabambino que el incremento de las propiedades rurales no fue resultado del asalto a las comunidades, sino de la subdivisión de las propiedades mayores ${ }^{44}$. Por último, en lo concerniente a los compradores, éstos fueron en su mayoría «soldados, enpleados públicos con haberes atrasados, parientes y paniaguados de los ministros de gobierno» ${ }^{45}$. Pero no sólo éstos compraron, sino también lo hicieron los indios, no siendo homogénea su reacción frente a las compras. Esto ocurrió, primero, porque, aunque las disposiciones del gobierno debían afectar por igual a todo el territorio, hubo diferencias regionales en su recepción e interés, siendo el departamento de La Paz uno de los más afectados; segundo, porque hubo indígenas acomodados interesados en comprar para librarse de los controles comunales y extender sus posesiones a expensas de otros $\operatorname{comunarios}^{46}$.

La situación anterior volvió a cambiar en torno a 1871, como resultado de la revolución promovida por Agustín Morales y Casimiro Corral para derrocar al presidente Melgarejo, en la que colaboró la población indígena, sobre todo la del departamento de La Paz, movilizada con el Decreto de 12 de noviembre de $1870^{47}$. Sin entrar a discutir los contenidos políticos de su participación, interesa subrayar que ésta estuvo ligada al proceso de venta de tierra del que habían sido objetos $^{48}$. Ello explica que en la Suprema Orden Circular de 19 de enero de 1871 el gobierno señalase que los propósitos de la revolución habían sido «devolver a esos infelices sus garantías individuales y su propiedad», sin que subsistiesen

44 RodrigueZ (22), p. 190; Robert H. JACKSON, «Cambios en la tenencia de la tierra en la provincia de Cliza (1860-1930) y orígenes de los sindicatos campesinos bolivianos», Historia y Cultura, no. 18, p. 101; Alberto RIVERA PIZARro, Los terratenientes de Cochabamba. Cochabamba, CERES-FACES, 1992, p. 81.

45 Ramón SOTOMAYOR VALDES, La legación de Chile en Bolivia desde septiembre de 1867 hasta fines de 1870. Santiago de Chile, Imp. Chilena, 1874.

46 LANGER (9), p. 72.

47 «No somos nosotros los que hemos levantado a los indios... Las usurpaciones, violencias, depredaciones y asesinatos que han sufrido los han obligado a defenderse; y esa insurrección de más de cincuenta mil indios ha estatuído para lo futuro la necesidad imperiosa de llamar la preferente atención de los legisladores sobre su triste y lamentable situación, semejante a la de los parias o a la de los ilotas» (Memoria de Casimiro Corral a la Asamblea Constituyente. Sucre, 18 de junio de 1871. Citado en BARNADAS (29), p. 55.

48 «La revolución operada por los pueblos contra el despotismo y la usurpación entraña, entre sus fecundos y benéficos resultados, el de proteger y amparar en sus derechos a la desgraciada clase indígena; en la reconquista de las libertades y garantías públicas esa clase ha llevado el contingente de su concurso espontáneo y ha corrido todas las visicitudes y azares de la campaña. El triunfo obtenido debe ser el triunfo de sus legítimas aspiraciones, la adquisición de sus tierras, de que fue violentamente expropiada» (ANB. Circular del 29 de abril de 1871. Actos Administrativos, 18701871, p. 131. Ibidem).

R. I., $1999, \mathrm{n}^{\circ} 217$ 
más obligaciones que las que tenían respecto a la Iglesia y al Estado. Por ello se instaba a los prefectos a que hiciesen comprender a los indígenas comunarios que se hallaban en plena posesión de los antiguos derechos que gozaban de sus terrenos y que podían volver a sus tareas tradicionales, no siendo por tanto necesarias las «centurias y compañías de indios». A esas medidas se unieron la Orden del 1 de marzo de 1871, la Orden Circular de 10 de abril de 1871 y la Orden del 13 de abril de 1871 por las cuales los compradores estaban facultados para recoger sus pertenencias y cosechas sin tener derecho a las tierras ${ }^{49}$. Las Leyes de 31 de julio y de 9 de agosto de 1871 vinieron a ratificar las anteriores, primero, al reconocer que los indígenas originarios siempre fueron propietarios de las tierras de comunidades $\mathrm{y}$, segundo, al anular las ventas y enajenaciones de tierras ordenadas por Melgarejo, siempre que los interesados probasen ante los tribunales haber cumplido los requisitos exigidos por leyes y decretos anteriores al 18 de diciembre de 1868 .

Aunque los nuevos dirigentes reconocían el valor del apoyo indígena en su triunfo, y que tal ayuda provenía del deseo de recuperar sus tierras, coincidían con sus predecesores en que las comunidades eran un anacronismo colonial que debía ser eliminado, por lo que mediante la Circular de 1 de septiembre de 1871 se abolió el sistema de posesión comunal. Para terminar con la posesión colectiva de la tierra se estimó necesario establecer por la Orden Circular de 25 de abril de 1872 el statu quo de las tierras indígenas anterior a la venta decretada por Melgarejo y a partir de él realizar un repartimiento proporcional de tierras entre los indígenas, para luego reglamentar las condiciones que éstos debían cumplir en el ejercicio de sus derechos individuales. Esa disposición fue suspendida por la Resolución Suprema de 16 de septiembre de 1873 de Adolfo Ballivian ${ }^{50}$.

Aunque los preceptos legales favorecieron a los indios, lo ocurrido en 1866 centró el debate sobre el porvenir de las comunidades de la década anterior en una discusión sobre si la prosperidad agraria se vería más garantizada por la existencia dominante de las haciendas o de la pequeña propiedad; que en lo relativo al tema de la ciudadanía indígena se tradujo en qué resultaba más beneficioso para lograr la civilización del indio, ¿su conversión en colono o en pequeño propietario?. La primera opción fue avalada por los compradores, que insistieron en que impedir el crecimiento de las haciendas supondría «reducir a cadenas la industria productiva para colocar en su lugar otra estéril» ${ }^{51}$. Además, la baja productividad de las comunidades y su economía de subsistencia ${ }^{52}$ impedían la for-

\footnotetext{
49 ANTEZANa (8), pp. 110-116.

50 Idem, pp. 124-129.

51 Juan de dios ZamBrana, Compradores de terrenos. Dos palabras sobre la venta de tierras realengas a la Nación, a la soberana Asamblea y al supremo gobierno. Cochabamba, Imp. Gutierrez, 1871.

52 Silvia Rivera argumenta para el caso potosino que la ruina del comercio triguero regional debilitó la capacidad de los ayllus y determinó su reconversión hacia una economía de subsistencia, no siendo ésta un rasgo inherente y constitutivo de la organización del ayllu (Silvia RIVERA
} 
mación de hombres libres, siendo el paternalismo del patrón y la eficiencia agrícola de las haciendas lo que posibilitaría a la larga su mejora social. Lo contrario, devolverle la posesión de las tierras era «cerrarle el camino de la ilustración», porque mientras se mantuviese como «comunero, cediendo a las tendencias de su carácter taciturno», viviría aislado, sin «aprender cosa alguna que pudiera dignificarlo». En cambio, en «su calidad de terrasguero» tendría que habitar las ciudades por temporadas y vivir al lado de su patrono, resultando de ello la modificación de «sus propensiones características de negligencia y de aislamiento» y la conversión «por la imitación de ejemplos que ha visto, en otro hombre del que fue». Por último, un requisito para su ciudadanía consistía en que pudiera compartir con sus vecinos un proyecto de construcción nacional, situación que parecía difícil debido a que con la revolución la guerra de castas había sido «atizada sin meditación, sin causal, sin justicia y tan sólo por una conveniencia pasajera», dando lugar a un «indígena desmoralizado, insolente y hasta atrevido» ${ }^{53}$. Es decir, el hecho de que su presencia en la revolución le hubiera llevado a creerse autorizado «en la política» ${ }^{54}$ dificultaba su integración local.

Conocedores de que las tasaciones habían sido «arbitarias a la voluntad de los compradores» ${ }^{55}$, José María Santivañez ${ }^{56}$ y Bernardino Sanjinés ${ }^{57}$ también temieron un alzamiento general de los indios, por lo que propusieron para evitarlo la restitución de sus terrenos y declararlos propietarios de los mismos, pero sólo cuando adquirieran la instrucción primaria. Aunque esa afirmación conllevaba reconocer que la educación indígena y, por tanto, el progreso nacional, eran reponsabilidades «blancas»,

«Instruidlos, levantad de sus encorvados hombros el peso de la opresión y entonces sólo entonces tendríais derecho para increparlos»

la diferencia con la opción de convertir a los comunarios en colonos residió en hacer también responsables del atraso de la agricultura a aquellos comprado-

CUSICANQUi y equipo THOA, Ayllus y proyectos de desarrollo en el norte de Potosí. La Paz, Ed. Aruwiyiri, 1992, pp. 42-43).

53 La defensa de los intereses del pueblo ante la Honorable Asamblea Constituyente de 1871, por dos abogados de La Paz. La Paz, Imp. del Siglo XIX, 1871, pp. 14-17.

54 Quintín Quevedo, La campaña de Bolivia en fines de 1870 y principios de 1871. Tacna, Imp. El Progreso, 1871, p. 23.

55 Manuel María CALlejo, Un vecino de Chayanta. La propiedad de los terrenos originarios y la injusticia de las ventas de ellos, ante el juicio de la Nación. Sucre, Imp. Pedro España, 1871.

56 José María SANTIVAÑEZ, Reivindicación de los terrenos de comunidad o sea refutación del folleto titulado «Legitimación de las compras de tierras realengas». Cochabamba, Imp. del Siglo, 1871 .

57 Bernardino SANJINES URIARTE, «Venta de las tierras de comunidad». Arículo escrito para $E l$ Republicano. La Paz, Imp. Paceña, 1871.

R. I., $1999, \mathrm{n}^{\circ} 217$ 
res de tierras, que gozando «de todas las ventajas de la civilización», no hubieran adquirido un mejor arado y que no se hubieran liberado de la rutina legada por los españoles ${ }^{58}$. Avelino Aramayo, consciente de las condiciones del agro en la provincia de Chichas (Potosí), señaló que el problema para su desarrollo no eran las comunidades, sino los tributos y cargas fiscales ${ }^{59}$ que gravaban a los nativos, por lo que propuso que se aboliesen. También sugirió que se les concediera la plena propiedad, por considerar que el dinamismo del sector rural no consistía en la formación de grandes haciendas, sino en la transformación del comunario en un próspero campesino parcelario, ya que la producción indígena siempre había sido la más barata. En opinión de Aramayo, los aportes diarios del indio a la sociedad le hacían «en cuanto a nacionalidad, tan boliviano ... como el Presidente de la República, en cuanto a ciudadano ... con iguales derechos que él, en cuanto hombre útil a la sociedad ... en mucho más útil que él y en cuanto a propietario, sus títulos son mucho más legítimos que los del primer propietario de Bolivia» ${ }^{60}$. De nuevo, pese a la diversidad de opiniones, hubo consenso en torno a la necesidad de acabar con la propiedad comunal de la tierra.

Respecto a si las tierras compradas durante la presidencia de Melgarejo fueron devueltas a sus antiguos poseedores, Herbert Klein, Erick Langer, Robert Jackson y Erwin Grieshaber indican que hubo variaciones regionales. Mientras la movilización índigena a favor de la revolución en el área de La Paz favoreció la disolución de las haciendas recién formadas, en el sur, donde los indios no estaban armados ni ayudaron a la revolución, los compradores ganaron casi todos los juicios a las comunidades. Pero, aunque el sostenimiento individual de las disputas en los juzgados, las deudas resultantes con los abogados, los impuestos y el adeudo de mercaderías a los comerciantes obligaron a muchos indígenas a vender sus tierras, eso no significó la desaparición de las mismas. Por un lado, las comunidades no pudieron ser compradas como unidad, tanto porque el sistema de herencia español obligaba a realizar múltiples compras parciales, como porque los compradores se limitaron a adquirir sólo parcelas continuas al poseer una concepción unitaria de su propiedad y no por pisos ecológicos. Por otro, su disgregación dependió de su tamaño, recursos, acceso a la economía monetaria y cercanía a nucleos urbanos y vías de comunicación. Además, los indios también actuaron como compradores de tierras de origen, habiendo entre 1896 y 1904 veintiún

58 Un vecino de Chayanta. La propiedad de las tierras de originarios y la injusticia de las ventas de ellos ante el juicio de la Nación. Sucre, 1871, pp. 13-14. Citado en BARNADAS (29), pp. 52-53.

59 De la misma opinión véase Plácido Orosco, Estudios financiales de Bolivia. Cochabamba, Imp. del Siglo XIX, 1871. 21-23.

60 Avelino ARAmayo, Apuntes sobre el Congreso de 1870. Sucre, Tip. del Progreso, 1871, pp.

R. I., 1999, n. $^{\circ} 217$ 
trasacciones de este tipo ${ }^{61}$. Para el caso cochabambino Gustavo Rodríguez señala que en el valle no se produjeron conflictos de significación como en el altiplano paceño, debido a que la ley de exvinculación ayudó a «desatar los anhelos y tendencias acumuladas hacia una campesinización deseada por todos». Las disposiciones estatales fueron bien recibidas por los comunarios, en la medida que eran campesinos medios y ricos a los que la vigilacia estatal limitaba su potencial crecimiento a costa de las tierras comunales. Si bien, la crisis regional y la contracción mercantil de fines de 1870 bloquearon el desarrollo embrionario de ese sector, ello tampoco redundó en la generalización del sistema de haciendas, debido a que sus propietarios tuvieron dificultades para pagar sus créditos y se vieron obligados a vender parte de sus propiedades; lo que favoreció el minifundio en la región ${ }^{62}$.

La permanencia de comunidades no significó la ausencia de variaciones significativas en cuanto al lugar del indígena en el proceso nacional. Pese a que no dominaron las opiniones a favor de «arrancar estos terrenos de manos del indígena ignorante, o atrasado, sin medios, capacidad o voluntad para cultivar, y pasarlos a la emprendedora, activa e inteligente raza blanca, ávida de propiedades» ${ }^{63}$, la imagen del indígena como sujeto público sufrió variaciones. Si bien se dijo que los indígenas eran la «única clase productora» que tenía deberes pero no derechos y que era «una clase sin redención y para la cual eran negativos los grandes principios proclamados por el evangelio y la civilización, pues viviendo en un país democrático y a la sombra de la cruz de Cristo, no había para ella ni caridad, ni igualdad, ni fraternidad», se trató de una fórmula paternalista que insistía en su minoría de edad pública y no en su madurez ciudadana. Por tanto, la denuncia de su discriminación no condujo a considerarla parte del «pueblo soberano de quien debía emanar todo poder» en un sistema republicano con «perfecta igualdad de derechos y deberes». Al contrario, la propuesta de los que lamentaban su opresión fue negarle, además de los derechos, los deberes; esto es, bajo criterios de piedad le redujeron toda posibilidad de alegar su trabajo como forma de participación en la construcción nacional ${ }^{64}$.

¿Qué influyó en el progresivo retroceso de la visión del indígena como ciudadano?. Por una parte, la actitud reivindicativa de los indígenas generó en la sociedad englobante miedo y desconfianza ante sus posibilidades públicas, adqui-

61 Herbert KLEIN, Ayllus y haciendas en el mercado boliviano en los siglos XVIII y XIX. Buenos Aires, Fundación Simón Rodriguez-Ed. Biblos, 1988, pp. 45-63; LANGER (22), pp. 70-75; Erick D. LANGER y Robert H. JACKSON, «El liberalismo y el Problema de la tierra en Bolivia (18251920)». Siglo XIX, México, 1990, pp. 9-32; Erwin P. GRIESHABER, «Resistencia indígena a la venta de tierras comunales en el departamento de La Paz, 1881-1920». Data. Revista del Instituto de Estudios Andinos y Amazónicos, no. 1, La Paz, 1991, pp. 113-143.

62 RodrigueZ (22), pp. 192-199.

63 Cita de José Vicente DORADO, 1864, en Silvia RIVERA, «Oprimidos pero no vencidos». Luchas del campesinado aymara y qhechwa de Bolivia, 1900-1980, Ginebra, Unrisd, 1986, pp. 13-14.

64 Ligeras consideraciones sobre la actualidad de Bolivia, s/1, 1874, pp. 8-43. 
riendo sucesiva fuerza la narrativa de la guerra de razas y con ella la concepción de que la heterogeneidad cultural del país conduciría a una sangrienta confrontación de razas y no a una unidad nacional. La consecuencia fue que se acentuó la imagen atrasada, bárbara y bestial del indígena, cada vez más difícil de imaginar como ciudadano de Bolivia ${ }^{65}$. Además, en la medida que ser indio dejó de ser una ventaja para el acceso a la tierra, la distancia cultural entre éste y el resto de bolivianos se amplió. Por otra parte, el razonamiento indio acerca de que su necesidad de tierras en diversos pisos ecológicos era para pagar el tributo perdió importancia, al poseer el Estado nuevas fuentes fiscales que le permitían aceptar su abolición. La consecuente despreocupación tutelar del Estado respecto a los indios modificó la tradicional visión sobre su ciudadanía basada en servicios al erario público ${ }^{66}$. Aunque eso afectó de modo general a su percepción y recepción sociales, es preciso tener presente, primero, que el antiguo tributo sólo fue suprimido en las áreas donde hubo revisitas, produciéndose el fenómeno de la percepción paralela del impuesto antiguo y el nuevo impuesto territorial ${ }^{67}$; segundo, que las contribuciones comunales fueran asimiladas por los Tesoros Departamentales, lo que según Tristan Platt se tradujo en un renovado pacto de reciprocidad entre el Tesoro Departamental y los indígenas ${ }^{68}$.

Tras un acalorado debate en el que confluyeron diversas opciones regionales sobre cómo concretar esa medida, en 1874 la Convención Nacional aprobó el proyecto de los convencionales chuquisaqueños ${ }^{69}$, conocido por Ley de Exvinculación de 5 de octubre de 1874. Bajo el principio de que «el indígena poseedor de tierra que cultiva, sin todos los derechos que imprimen su verdadero sello a la propiedad... no podrá salir nunca de la abyección ni elevarse al rango de ciudadano», sus presupuesto básicos fueron, primero, la declaración de que los terrenos

65 Este proceso se concretó a partir de la presencia aymara como ejército auxiliar de los liberales en la Guerra Federal de 1899. Véase Marta IRUROZQUI, «La masacre de Mohoza, 1899: la (re)invención de una tradición». Revista Andina, no. 22, CBC, Cusco, 1993; «Los hijos del miedo. Crisis y reajuste de la identidad nacional boliviana». Estudios de Historia Social y Económica de América, no. 17, Alcalá de Henares, Universidad de Alcalá de Henares, 1998.

66 «Martin Espadero, viudo de la clase de forasteros del Aillo Alapicha... espongo que... deseando robustecer el derecho de propiedad he servido seis meses en el Tambo de Ocurí, siendo así que este serbicio pertenece únicamente a los agregados y no a los forasteros...pido que se me de pase a la clase de agregados en mi mismo aillo...cumplo con mi deber, pues no hago más que aumentar mi contribución cuando antes veinte reales, poseyendo siempre el mismo terreno: el fin que me propongo es dar aumento al Erario Nacional». (ANB. Revisitas. Revisita de Chayanta 1877. Citado en Tristan PlatT, Estado boliviano y ayllu andino. Tierra y tributo en el norte de Potosí. Lima, IEP, 1982, p. 61).

67 BaRnadas (29), p. 329.

68 PlatT (67), pp. 134-135.

69 Proyecto de ley sobre la propiedad de las tierras de origen. Sucre, tip. del Progreso, 1874; Informe y proyecto de ley presentado por la Comisión de Hacienda a la Asamblea Legislativa de 1874 prorrogando por seis meses el plazo establecido por la ley de 9 de agosto de 1871 que anuló la venta de tierras indigenales. Sucre, Tip. del Progreso, 1874. 
que los indígenas poseían en «clase de originarios, forasteros, agregados o con cualquiera otra denominación», serían de su propiedad previa mensura, distribución y pago de 5 a 50 bolivianos; segundo, la negación de la existencia legal de las comunidades, de manera que ningún individuo o reunión de individuos podría «tomar el nombre de comunidad o ayllo, ni apersonarse por estos ante ninguna autoridad»; tercero, la implantación de un impuesto general a la propiedad de la tierra; cuarto, la exención de los servicios forzados exigidos por autoridades políticas, militares y eclesiásticas, aunque esto no afectaba a las relaciones entre hacendados e indígenas. Si bien el libre ejercicio del derecho de propiedad de los indios y la organización de una Revisita General de tierras en toda la República perseguían el fortalecimiento de una amplia capa de campesinos parcelarios frente al sistema latifundista, el hecho de que el Estado abandonase su función tutelar de los indígenas y les declarase sujetos jurídicos del derecho civil les dejó inermes frente a las presiones individuales de sectores privados externos, es decir, sometidos a la dinámica del mercado de tierras que afectaba a todos los bolivianos. Por tanto, la consolidación de los derechos civiles no les condujo necesariamente al disfrute de la ciudadanía, sino a la pérdida de la misma. Al no poder conservar su estatus de propietarios, se transformaron en colonos, luego en domésticos o dependientes, o emigraron a las ciudades engrosando las filas de los «vagos» o personas a las que no se les conocía «oficio, ocupación, destino, bienes, rentas ni modo de vivir honesto» ${ }^{70}$.

Aunque Gustavo Rodríguez señala que la Ley de Ex-vinculación se realizó parcialmente en los departamentos de Tarija y Cochabamba ${ }^{71}$, «la absoluta deficiencia y penuria en que se hallaba el Estado» para cumplir con los gastos que demandaba su ejecución, unidos a la suceptibilidad de los indígenas, dificultó que se llevara a cabo. Además, el general Hilarion Daza emitió las Resoluciones Supremas de 5 de febrero de 1877 y de 28 de marzo de 1877, por las que se prohibían las ventas de tierras de origen y se restablecían las normativas del gobierno de Agustín Morales, y decretó el 11 de marzo de 1879 un Código Rural. Ello no impidió que, ante las necesidades financieras emergentes de la Guerra del Pacífico (1879-1883), el Consejo de Ministros, mediante el Decreto de 16 de septiembre de 1879, ordenase la ejecución de una Revisita General responsable, primero, de declarar pertenecientes al Estado para su posterior venta o arrendamiento a todos los terrenos rurales cuyos títulos de propiedad no fueran presentados ante los funcionarios; y segundo, obligar a pagar a los indígenas valores muy elevados para consolidar la propiedad absoluta de sus tierras ${ }^{72}$.

70 Rossana BARRAGAN, «La época del artesano culto: la lucha por la educación y la ciudadanía en la ciudad de La Paz (1845-1855)». I Coloquio Internacional, El siglo XIX en Bolivia y América Latina, Sucre, 1994, (versión preliminar) , p. 14.

71 RodRIGUEZ (22), p. 135

72 ANTEZANa (8), pp. 137-142 
De nuevo en la Convención Nacional celebrada del 2 de junio al 20 de septiembre de 1880 volvió a plantearse si los terrenos de comunidad eran propiedad del Estado o de los indígenas. Como en veces anteriores, esas preguntas conllevaban una interpretación de las comunidades como contrarias al espíritu liberal bajo el supuesto de que el patriotismo republicano era contrario a las lealtades corporativas. En la medida que los indios se organizaban en comunidades su sentimiento ciudadano carecía de exclusividad nacional y, por tanto, quedaban invalidados para ejercer la ciudadanía, siendo sólo su conversión en propietarios individuales o colonos lo que les abriría paso a la civilización. En este sentido se afirmaba la idea de que la tributación hecha al Estado por el indio en calidad de comunario no le otorgaba la ciudadanía, pero sí la contribución realizada como campesino independiente, vinculado al mercado, productor y consumidor. Aunque no hubo voces disidentes respecto a la abolición de las comunidades, reapareció el debate sobre si su conversión en pequeño propietario garantizaba el desarrollo agrario o resultaba más conveniente su transformación en colono. A favor de esta última opción se argumentó que gracias a ello los indígenas no sólo se aproximarían a la sociedad y al trato de "clase ilustrada», venciendo su aislamiento y las «veleidades» criminales provocadas por el medio ambiente del Altiplano, sino que también ganarían la protección del hacendado que les eximiría de las exacciones y pleitos de los que eran víctimas gracias a los lazos filiales que se establecerían entre ambos ${ }^{73}$. En lo relativo a la ciudadanía, la consecuencia sería la conversión de los indígenas comunarios en domésticos. Aunque recibieran de sus patrones la educación primaria necesaria para hacerles válidos para la convivencia con la población blanca, ésta no podría convertirles en bolivianos con voto y decisión porque su trabajo les relegaba a un estatus de «menores de edad», vulnerables a los gustos y necesidades del patrón, luego incapaces de ejercer actos políticos con la responsabilidad que fijaba la independencia de acción.

Pese a que el colonato contó con más adeptos que en discusiones anteriores, la decisión tomada por la Convención fue la conversión de los comunarios en pequeños propietarios. Ante esta situación, era de suponer que aquellos indígenas que hubieran logrado actualizar sus títulos de propiedad y que, por tanto, no pudieran ser englobados en la categoría de forasteros o vagos o agregados sin tierras, tuviesen derecho a la ciudadanía. De hecho en la Convención de 1880 se dijo que si los indígenas «acaso no ejercen los derechos políticos, es porque no saben leer y escribir, si no ejercen es por ignorantes: el derecho civil también lo ejercen y son actos que reconoce la constitución» ${ }^{74}$. El hecho de que «el aborigen

73 APLP. Colección León Maria Loza. Posesión y ventas de tierras de propiedad indígena. Extracto de opiniones valiosas del Redactor de la Convención Nacional de 1880, emitidas por los Honorables Convencionales de ese año. Sobre el derecho que tiene el Estado para vender las tierras de comunidad poseídas por los indígenas. La Paz, 1880, f. 1 y 9-9v.

74 Redactor de la Convención Nacional del año 1880. La Paz, Litografía i Imprentas Unidas, 1926, tomo II, p. 424.

R. I., $1999, \mathrm{n}^{\circ} 217$ 
al entrar en el rango de propietario de sus tierras» asumía los derechos civiles quedó reafirmado en uno de los proyectos del Decreto presentado por la Comisión de Revisitas a la Prefectura de La Paz, donde se dijo que como ello no implicaba gozar de los derechos políticos, se recomendaba que los indígenas fueran exonerados del servicio militar obligatorio «puesto que ellos no han sido ni son ciudadanos ... en cuanto al ejercicio del derecho político del sufragio y al desempeño de funciones públicas» ${ }^{75}$. Dado que se le reconocía como propietario agrícola, el único impedimento presente en la constitución y los reglamentos electorales para actuar como ciudadano de la República estaba en su condición de analfabeto. Probado lo contrario, podían ejercer los derechos políticos, como muestra la información aportada por Ramiro Condarco sobre el tradicional apoyo político como votantes de los comunarios de Peñas al Partido Conservador ${ }^{76}$. Pese a que la escasez de testimonios como el anterior imposibilita establecer afirmaciones rotundas sobre la presencia indígena en las urnas, eso no impide señalar que la negativa a la participación electoral indígena por su «inconsciencia» no estaba reñida con el derecho que tenían a ser representados. El reclamo de las provincias con mayor población india de aumentar el número de sus diputados, llevó a que este pedido se realizara en las Cámaras bajo el argumento de que los indios deberían estar más representados porque sus ingresos al Estado así lo ameritaban ${ }^{77}$. Esa situación y el hecho de que el impedimento fundamental para la ciudadanía fuese ahora la educación explican por qué muchas de las reivindicaciones indígenas sobre devolución de tierras e implantación de escuelas en las comunidades y haciendas fueron acompañadas de alusiones y exigencias a sus representantes y también que éstas estuvieron orientadas a reclamar que el Estado cumpliera con su obligación constitucional de asegurar educación primaria para todos los bolivianos. El deseo indio de instrucción, interpretado como voluntad de tener presencia pública en el devenir nacional, aclara también por qué al tiempo que existía un esfuerzo indígena por asimilarse a las formas de convivencia de la mancomunidad criolla-mestiza existió por parte de ésta un afán de invisibilizarla públicamente a través tanto de condenarla a una criminalidad innata explicitada en su deseo de una guerra de razas, como de convertirla en una población eternamente infantil incapaz de comprender el juego político. Ambas posturas aunque no negaban al indio como boliviano, le impedían un papel activo en la confección de la nación, recluyéndole en una imagen esencialista y apolítica que lo imposibilitaba como ciudadano.

Como resultado de lo estimado en la Convención Nacional, se decidió realizar otra revisita, estableciéndose en la Circular del 17 de diciembre de 1880, ex-

75 Orden 24 de noviembre. El Comercio, La Paz, 14 de enero de 1882.

76 Proceso Peñas, c. 6º f. 183 v. (Ramiro Condarco Morales, Zárate, el temible Willka. Historia de la rebelión indígena de 1899. La Paz, Imp. Renovación, 193, p. 435).

77 Redactor de la Cámara de diputados. La Paz, Imp. de El Nacional, vila Hnos editores, tomo I, 1883, pp. 508-9.

R. I., $1999, \mathrm{n}^{\circ} 217$ 
pedida por Eliodoro Villazón, ministro de Hacienda, que los corregidores recorrieran las comunidades bajo su jurisdicción y reuniesen «a todos los indígenas de todos los aillus» para hacerles comprender el decreto que la reglamentaba. Asimismo, «los párrocos, corregidores, alcaldes y curacas y cuantos individuos inteligentes y de influjo» debían propagar «entre la indiada el convencimiento» de su «inmenso beneficio» ${ }^{78}$. Ladislao Cabrera, Secretario de Estado del presidente Narciso Campero, fue el encargado de llevar a cabo la revisita y con ella aumentar los fondos públicos del erario nacional. Conforme al espíritu de la ley de $1874^{79}$. dispuso dos medidas que afectaron negativamente la posibilidad de que los antiguos comunarios se asentaran como propietarios de sus posesiones tradicionales. Primero, el título de propiedad costaría a cada antiguo comunario de 5 a 10 bolivianos; segundo, hasta que se hiciese efectiva la distribución de títulos de propiedad los indios debían seguir pagando el tributo, pero ya no en pesos sino en bolivianos, con el agravante de que si el antiguo peso constaba de ocho reales, un boliviano equivalía a diez, con lo que el cambio implicaba un aumento del $25 \%$ del tributo. Este se suprimiría una vez adquirida la tierra, quedando los excomuneros sujetos al impuesto de propiedad general a todos los bolivianos ${ }^{80}$.

En enero y febrero de 1881 los revisitadores intentaron cumplir el decreto en el departamento de $\mathrm{La} \mathrm{Paz}$, pero la animosidad de los indígenas en un momento de extrema fragilidad nacional como era la guerra con Chile obligó al presidente a suspender la revisita. Establecida una tregua, Campero volvió autorizarla el 18 de mayo de 1881, sin embargo, ante las noticias de que la venta de tierras estaba siendo realizada bajo presión, el 30 de diciembre de 1881 el presidente suspendió la recaudación del tributo en bolivianos, la autorizó en pesos y permitió la venta de títulos de propiedad proindiviso. Esto significó que los miembros de las comunidades indígenas podían adquirir sus títulos al unísono y no sujetos a la división individual de la tierra, de manera que la comunidad podía mantenerse intacta funcionando como una unidad social y pagando el tributo de la manera acostumbrada, aunque lo indiviso no la permitía actuar como entidad legal. A esas medidas se unió el 22 de febrero de 1883 la prohibición del cobro de la contribución a los indígenas sin tierras ${ }^{81}$. En septiembre de 1884 el gobierno cambió su deci-

78 ANTEZANA (8), 169.

79 «Las tierras pertenecientes a los originarios constituían una considerable parte del territorio de la República. Para poner sus bienes en circulación, ponerlos en manos de propietarios inteligentes y capitalistas era el intento de la legislación de 1874; y si la ley era puesta en práctica, se conseguiría un considerable incremento de los bienes públicos y de la percepción agrícola» (Ladislao CABRERA, Memoria presentada a la Convención Nacional de 1880 por el Secretario de Estado..., La Paz, 7 de junio de 1880, pp. 18-19).

80 El Comercio, La Paz, 6 de julio de 1881; Manuel Rigoberto PAREDES, La altiplanicie. Anotaciones etnográficas, geográficas y sociales de la comunidad aymara, ed. Isla, La Paz, 1965, pp. 170-171.

81 La aplicación de esa ley no fue inmediata, ya que se seguía cobrando en 1897. En cuanto a la contribución territorial de indígenas instituida por la ley del 5 de octubre de 1874 y modificada 
sión. Consideró que la propiedad de cada indígena debería ser sometida a las formas revisitarias sujetándolas al régimen individual y en ningún caso proindiviso y trató de recaudar el tributo en bolivianos. Aunque en octubre de 1885, líderes indígenas de La Paz, Oruro y Potosí pidieron al Senado abolir el incremento del $25 \%$ y abrogar la ley de revisitas, el ejecutivo lo rechazó el 14 de octubre de 1885. Las revueltas se sucedieron hasta que el gobierno suspendió el aumento del $25 \%$ el 17 de mayo de 1886 y ordenó que el título proindiviso iría a costar a cada propietario de la comunidad la unidad monetaria mas baja en bolivianos el 16 de noviembre de $1886^{82}$.

$\mathrm{Si}$ bien los indígenas tuvieron éxito en lo referente a las disposiciones monetarias, no sucedió así con la venta de tierras. Las comunidades situadas en las tierras que bordeaban el lago Titicaca, en los fértiles y húmedos valles de la cordillera Occidental o próximas a los mercados urbanos de La Paz fueron las más perjudicadas ${ }^{83}$. Esta situación vino acompañada por innumerables acciones judiciales que mostraban la resistencia indígena a que sus aportaciones al Estado no implicaran que éste volviera asumir su función tutelar y les defendiera frente a los compradores particulares. La carta dirigida el 15 de febrero de 1886 al prefecto de $\mathrm{La} \mathrm{Paz}$ por los comunarios del ayllu Irpa-Chico, situado en el cantón Viacha ( $\mathrm{Pa}-$ cajes), por el contencioso con el comprador Felipe Pinilla lo ejemplifica:

«Cada raza tiene sus distintas costumbres sociales; igual que nosotros la generación venidera debe también estar sujeta a los mismos servicios y trabajos que nosotros hemos tenido. La ley de revisita nos informó sobre nuestros derechos y prohibió la violencia y toda imposición; pero no nos permitió actos voluntarios. Ahora queremos serle útiles a nuestra localidad de modo que estas mismas autoridades, en cumplimiento de sus deberes nos den las garantías de la constitución del Estado que nos corresponden por derecho y van en contra de aquellos que nos amenazan y se llaman a sí mismos compradores de nuestras tierras, como actualmente está ocurriendo con el Sr. Felipe Pinilla, quien explotó nuestra ignorancia, al llevar a cabo un contrato muy opuesto a los términos de nuestro entendimiento; esta es la razón por la que estamos siguiendo un juicio a fin de obtener la anulación de la venta de tierras. Está entre nuestros derechos subordinarnos al servicio del Estado y desde este momento vamos a asumir todos esos trabajos públicos, como apoyar al ejército, con lo cual servimos a todos los ciudadanos del común ${ }^{84}$.

por las de 1 de octubre de 1880 y 30 de junio de 1911, varios departamentos siguieron considerándola una de sus principales fuentes de ingresos hasta bien entrado el siglo XX (SANCHEZ ALBORNOZ (7), pp. 214-15).

82 Grieshaber (62), pp. 117-119; Platt (67), pp. 79-100

83 Herbert KLEIN, «La estructura de las haciendas a fines del siglo XIX en Bolivia: las provincias del norte del lago Titicaca». Data. Revista del Instituto de Estudios Andinos y Amazónicos, no. 1, La Paz, 1991, pp. 52.

84 ADLP. Prefectura, cajón 1886, expedientes. Citado en PLATT, p. 122.

R. I., 1999, n. ${ }^{\circ} 217$ 
Las esfuerzos judiciales de los indígenas fueron mal recibidos por las autoridades a juzgar por la Circular del 17 de marzo de 1886, en la que sus reclamaciones se consideraron «un extravío de ideas» no sólo por sus referencias a «las doctrinas del socialismo más desquiciador», sino porque proclamaban «abiertamente el derecho de resistencia a la ley». Como se consideraba imposible que un indio pudiera «abrigar semejantes doctrinas» se culpó de ello a los encargados de consignarlas. En consecuencia, se dictó que siempre que se presentaran «memoriales y solicitudes conteniendo semejantes doctrinas», los prefectos, subprefectos y fiscales mandasen «someter a juicio criminal no sólo a los indígenas a cuyo nombre se hicieren tales solicitudes, sino también al autor de los escritos» y al que apareciese «firmándolo a ruego» ${ }^{85}$. Si bien estas medidas constreñían la acción civil de los indígenas, su mención se debe a que revelaban cómo la competencia entre partidos se había trasladado al ámbito de las querellas indígenas, siendo cada vez más frecuente que abogados miembros de los partidos opositores, sobre todo el Partido Liberal, apoyasen a los indios en los tribunales. Los intentos de reforma agraria estatales, la oposición indígena expresada en rebeliones, juicios y alianza con las autoridades locales, unidos a la politización que los partidos hicieron del proceso, produjeron una crisis general que sólo mostraba la debilidad del gobierno para realizar un programa de desarrollo nacional:

«Desvinculada una parte de las tierras, manteniéndose la otra bajo el híbrido y pernicioso sistema de las comunidades, la administración pública no sabe a qué atenerse: colocada entre los despojos del sistema comunal viejo y los albores de la desvinculación o sistema nuevo, sufre la disminución progresiva de los ingresos; el orden social recibe los sangrientos sacudimientos de las colisiones en la campaña; las postas, las escuelas, las iglesias, los corregimientos, se hallan privados de los antiguos elementos de estabilidad y subsistencia...la gran necesidad del momento es la terminación de las revisitas» ${ }^{86}$.

Ante la imposibilidad de continuar la Revisita por no contar con una fuerza burocrático-militar que controlase los abusos en el reparto de títulos de propiedad, tasación de los terrenos y operaciones de compra-venta e impusiese la autoridad del Estado a indígenas, hacendados y vecinos de los pueblos, el ministro de Hacienda sugirió en 1891 que no se modificara el sistema tributario ${ }^{87}$, siendo los únicos objetivos la individualización de la tenencia y la creación de un mercado

85 Anuario de Leyes y Disposiciones Supremas, p. 84. Citado en BARNADAS (29), pp. 46-47.

86 BNB. Ministerio de Hacienda. Memorias, 1889. Informe del Ministro de Hacienda, Isaac Tamayo. Sucre, 1889, p. 24.

87 Tristan Platt señala que en 1890 el prefecto de Chayanta, Nicanor Serrudo dijo que «no se ha presentado ninguna inconveniencia, sin embargo de que se han suprimido los recaudadores, habiendo ejercido las funciones de éstos, personas nombradas de entre los mismos comunarios, con el título de curacas recaudadores». (PLATT (67), p. P39). 
de tierras, ya que con ello se terminaba con «el híbrido y pernicioso sistema de las comunidades», considerado como un «elemento exótico ... extraño al movimiento económico del país» ${ }^{88}$. Sólo una vez logrados tales fines se procedería a establecer un impuesto predial sobre la producción anual.

Pese a que la imposición de un impuesto único siguió siendo objeto de codicia estatal, la Mesa Revisitadora logró parcelar grandes extensiones de tierra antes de 1900. Ello se realizó en un clima de múltiples rebeliones e interminables demandas judiciales que tuvieron como transfondo el enfrentamiento entre conservadores y liberales. Tras la Guerra Federal de 1899, los indígenas se convirtieron discursivamente en un colectivo bárbaro, sangriento, inasimilable por la civilización occidental, y, por tanto, objeto de tutela. El desarrollo de esa imagen estuvo alimentado tanto por la presencia activa de los aymaras como aliados de los liberales, como por su derrota a manos de éstos una vez que quedó claro su triunfo sobre los conservadores. La desarticulación indígena garantizó que tras la guerra se realizaran la mayoría de las ventas, siendo el departamento de $\mathrm{La} \mathrm{Paz}$ donde hubo más comunidades completas enajenadas.

\section{CONCLUSIONES}

En los comicios presidenciales de 1917, el Partido Liberal expresó descontento ante la presencia indígena en la ciudad, preguntándose «por qué la indiada, que no ejerce el derecho de ciudadanía, puesto que es analfabeta, se había mezclado en cuestiones de política concurriendo a la plaza el día de las elecciones e (interviniendo) en asuntos ajenos a su îndole y a su grado de instrucción ${ }^{89}$. Aunque este comentario se realizó en un periodo distinto al que abarca el artículo, su mención resulta oportuna por resumir la dificultad fundamental del acceso indígena a la ciudadanía: su analfabetismo. Sin embargo, ese inconveniente no debe entenderse como el mero hecho de no saber leer y escribir en castellano, sino como el resumen de una interesección de variables que a lo largo del siglo XIX matizaron y cuestionaron la aptitud pública de esta población mediante su estigmatización cultural y social. Aunque las constituciones, códigos y reglamentos electorales no ofrecieron variaciones significativas entre 1839 y 1952 en cuanto a los requisitos de ciudadanía, pueden distinguirse dos tendencias al respecto que hacen referencia a la relación del Estado con los indígenas. Por un lado, el Estado hizo un esfuerzo de eliminar el estatus coporativo de indios y su entendimiento como un grupo con derechos colectivos, ya que el reconocimiento de una identidad étnica distintiva no sólo se juzgaba como una postura discriminatoria que revitalizaba una sociedad de castas, sino porque la existencia de «un estado den-

88 BNB. Ministerio de Hacienda, Memorias, 1896. Idem, p. 166.

89 «El resultado electoral del domingo», El Diario, La Paz, 8 de mayo de 1917. 
tro del Estado» era contraria al principio de homogeneidad cultural base de la «República de ciudadanos». Por otro lado, la dependencia fiscal del tributo, la oposición de los grupos exonerados tradicionalmente de éste a la política de uniformizar la contribución, y las dificultades del Estado para imponer esa medida y otras relacionadas con la supresión de las comunidades y la conversión de los indígenas comunarios en pequeños propietarios a través de revisitas confirmaron al Estado en el papel de administrador de la población indígena y a ésta como un hecho público.

El resultado de ambas tendencias en lo concerniente a aquellos aspectos que podían identificar a los indígenas como ciudadanos fueron la tributación y la posesión de la tierra, quedando en cuestión lo relativo a saber leer y escribir en castellano. Aunque su difusión era responsabilidad oficial, el hecho de que el Estado mantuviera una relación paternal con los indígenas ahondó la visión de éstos como sujetos que debían ser tutelados y defendidos y, por tanto, menores de edad o dependientes. Si bien ese rango garantizaba al indio cierta capacidad de lucha frente a agresiones exteriores, también le distanció del disfrute de la ciudadanía en la medida que contribuyó a alimentar la idea de su inferioridad racial. Las normativas relativas a crear instituciones judiciales destinadas a la defensa del indio o a prohibir la venta de sus terrenos hasta que supieran leer y escribir, unidas a la voluntad indígena de no perder sus prerrogativas grupales en un contexto cada vez más adverso, no sólo revitalizaron la concepción colonial de «miserable» o persona necesitada de guía, sino que la dotaron de nuevos contenidos que fueron afianzando el tópico de que la educación no bastaba para integrar al indio a la civilización. En la medida que el Estado encontró fórmulas que sustituyeran su importancia demográfica y fiscal y delegó su administración a las prefecturas y a los hacendados, aumentó el desamparo indígena, sobre todo porque cuanto mayor era su acceso al disfrute de los derechos civiles y políticos, menos podía aprovecharlos porque había perdido los resortes estatales que les defendían frente a las presiones del mercado. En consecuencia, los indios quedaron atrapados en un limbo jurídico sin defensas corporativas, a la espera de una instrucción orientada a convertirles en trabajadores útiles a la nación, ya que sólo así redimirían su pecado de incompatibilidad cultural y pasarían de ser simplemente bolivianos a convertirse en ciudadanos bolivianos. Por supuesto este panorama no fue uniforme, aunque sí lo fue la actitud de la sociedad englobante de considerar al indígena sólo objeto de discusiones y decretos ${ }^{90}$, en vez de sujeto activo en el diseño del Estado-nación. Paradójicamente, esta postura cobró fuerza cuando a través de rebeliones, acciones en los tribunales y lazos clientelares los indígenas demostraron no sólo conocimientos del funcionamiento de lo público, sino de-

90 Respecto a esta idea consúltese Andrés Guerrero, «Una imagen ventrílocua: el discurso liberal de «la desgraciada raza indígena» a fines del siglo XIX». Blanca Muratorio (Ed.), Imágenes $e$ imagineros. Representación de los indígenas ecuatorianos. siglos XIX y XX. Quito, flacso, 1994. 
seos y capacidades de participar y gestionar lo nacional. Aunque este tema no ha sido tratado de forma central en el artículo, su mención incide en la idea de que la historiografía que analiza cualquier acción india como resistencia a lo «occidental», preservación de lo propio o separatismo, sólo contribuye a la ocultación de su mayoría de edad social y política, sobre todo por olvidar la influencia que el discurso nacional tuvo en las respuestas indigenas.

This article studies the access of the Bolivian indigenous people to citizenship through the analysis of the legal regulations regarding the indigenous property of the land and their role as taxpayers, as well as the political and economical arguments in the context of the debate on the agrarian reform. The work is based on three assumptions: firstly, although illiteracy was the main obstacle for the Indians' accession to citizenship, this hindrance was lessened by the fact of their being taxpayers and by their legal situation vis a vis land property; secondly, the endeavour of the state to eliminate indigenous communities was due to a homogenizing aim based on the idea that cultural diversity was an obstacle for the development of the Republic and on the wish to attain a "nation of citizens»; and thirdly, there was a gradual decrease in the society's will to assimilate Indians as Bolivian citizens.

R. I., $1999, \mathrm{n}^{\circ} 217$ 